\title{
Bubble formation in liquid Sn under different plasma loading conditions leading to droplet ejection
}

\author{
W. $\mathrm{Ou}^{1}$, F. Brochard ${ }^{2}$, T.W. Morgan ${ }^{1}$ \\ ${ }^{1}$ DIFFER - Dutch Institute for Fundamental Energy Research, De Zaale 20, 5612 AJ Eindhoven, The Netherlands \\ ${ }^{2}$ Institut Jean Lamour, Université de Lorraine, UMR 7198 CNRS, 54011 Nancy Cedex, France
}

\begin{abstract}
Liquid metals have been proposed as potential divertor materials for future fusion reactors, and surface stability is a vital requirement for such liquid metal divertors (LMDs). Capillary porous structures (CPSs) have been applied to the design of liquid metal targets as they can avoid MHD instability by surface tension and provide a stable liquid surface. However, our previous work has found that liquid Sn surfaces can be very unstable in hydrogen plasma even in cases without magnetic fields. To increase our understanding of the interaction of liquid Sn surfaces with plasmas, in this work we systematically investigated the surface behaviors of liquid Sn in different plasma exposures in linear plasma devices, either in Nano-PSI at low flux and without magnetic field, or in Magnum-PSI with strong magnetic field strength. Surface instability leading to droplet ejection has been observed and recorded in the experiments. The ejection of droplets is not dependent on magnetic fields and plasma currents, and is found to be dependent on the plasma species and plasma flux and surface temperature. The CPS meshes applied in the experiments cannot completely avoid droplet ejection but can decrease droplet size and lower droplet production rate. In $\mathrm{H}$ plasma, droplets were observed once Sn melted even at low fluxes. For the case of $\mathrm{N}$ plasma, the appearance of droplets started at a temperature marginally higher than tin-nitride decomposition temperature. Only at high fluxes $\left(\sim 10^{23-24} \mathrm{~m}^{-2} \mathrm{~s}^{-1}\right)$ and high temperatures $\left(900-1000{ }^{\circ} \mathrm{C}\right)$ were a few droplets observed in Ar or He plasma. For all cases, the ejection velocities of most droplets were around $1-5 \mathrm{~m} / \mathrm{s}$. Bubble formation, growth and bursting in the plasma-species-supersaturated liquid $\mathrm{Sn}$ is proposed as the primary mechanism for the ejection of droplets. Plasma-enhanced solubility is responsible for the achievement of $\mathrm{H} / \mathrm{N}$-supersaturated liquid $\mathrm{Sn}$, while high plasma flux implantation is responsible for Ar/He-supersaturated liquid $\mathrm{Sn}$. Once the concentration of plasma species in liquid Sn reaches a certain supersaturation level, nucleation and growth of bubbles occur due to the desorption of dissolved plasma species from the liquid Sn. The formation and bursting of bubbles have been directly observed in the experiment. The sizes of most bubbles were estimated in the range of $40-400 \mu \mathrm{m}$ or even smaller. A bubble growth model based on Sievert's and Henry's laws is invoked to describe bubble growth in liquid Sn.
\end{abstract}

Keyword: Surface instability, Sn droplets, Bubbles, Free surface, Capillary porous structures

\section{Introduction}

Of late, liquid metals have attracted more and more attention as liquid plasma-facing materials (PFMs), especially for their application as liquid metal divertors (LMDs) in future fusion reactors [1,2]. Liquid metal (LM) based divertors can have a short distance to the coolant as they do not need an ablative layer due to their self-healing nature [2], meaning they can withstand high heat fluxes, and beyond this can handle very high heat loads through evaporation and formation of vapor shielding [3,4]. They could be also resistant to neutron radiation owing to their liquid nature and the reduction of thermal stress in the solid parts of the component [5]. However, when working as a PFM, very high plasma currents through LMs in a strong magnetic field, as is present in fusion tokamaks, can produce magneto-hydrodynamic (MHD) effects and cause liquid splashing from the surface [6-10]. In particular, plasma disruptions and edge-localized modes (ELMs) increase the current density in the liquid and can cause Kelvin-Helmholtz (KH) [11] and Rayleigh-Taylor (RT) [12] instabilities [13-15]. Such instabilities can lead to liquid metal splashing and to droplet ejection into the core plasma. In turn, these droplets can themselves lead to a strong increase in radiation and dilution of the plasma and can cause H-L back-transitions or disruptions [7, 16-18]. In order to mitigate the above phenomenon, capillary porous structures (CPSs) have been first applied to liquid lithium [19-21], which is historically the most widely studied liquid metal in fusion [22]. It has been shown that CPS design can significantly reduce the MHD effect and provide a stable liquid metal surface [12, 21, 22]. 
Liquid Sn provides some distinct merits compared with lithium. Owing to its low vapor pressure it has a wider operational temperature window. It is also not explosively reactive with water and air, unlike $\mathrm{Li}$, thus is much safer. A lower hydrogen isotope inventory in $\mathrm{Sn}$ is expected [23-25] as there is no stable hydride for Sn above room temperature [26], unlike for $\mathrm{Li}$ [27]. On the other hand, due to its high atomic number, the influx of $\mathrm{Sn}$ entering into the core plasma must be strictly limited to around $0.5 \%$ that of lithium [2]. In our previous experiments [25] surface instability of liquid Sn due to droplet ejection has been observed even for static liquid Sn exposed to unmagnetized plasmas. This instability was found to be strongly dependent on plasma species, quite different from MHD instability. Sn micro-droplet ejection upon hydrogen plasma exposure has also recently been reported in [28]. To assess liquid Sn as a liquid PFM, it is essential to determine the mechanism behind the instability behaviors observed in the experiments. In this work, we investigated the behaviors of both free surface (FS) and CPS Sn targets under different plasma exposures (H, N, He and Ar) in Nano-PSI and Magnum-PSI.

\section{Experiments}

Experiments were conducted in two different linear plasma devices, Nano-PSI [29] and Magnum-PSI [30]. Cascaded arc sources [31] were used to produce plasmas for both. Details about the devices can be found in [25]. Nano-PSI can produce low density and low temperature unmagnetized plasmas using different working gases, such as hydrogen, nitrogen, helium and argon. For hydrogen (nitrogen) plasma produced in Nano-PSI, it mainly consists of $\mathrm{H}_{3}{ }^{+}\left(\mathrm{N}_{3}{ }^{+}\right)$according to [32, 33], and the radical flux is around 2 orders of magnitude higher than ion flux [25]. The typical plasma temperature measured by double Langmuir probe at the beam center is $0.1 \sim 1 \mathrm{eV}$ and fluxes to the target for different plasmas are $\mathrm{Ar}^{+} \sim 10^{23} \mathrm{~m}^{-2} \mathrm{~s}^{-1}, \mathrm{He}^{+} \sim 10^{21} \mathrm{~m}^{-2} \mathrm{~s}^{-1}, \mathrm{~N}_{3}^{+} \sim 10^{21} \mathrm{~m}^{-2} \mathrm{~s}^{-1}$ and $\mathrm{H}_{3}^{+} \sim$ $10^{20} \mathrm{~m}^{-2} \mathrm{~s}^{-1}$. A heater is connected to target holder in Nano-PSI that is used to pre-heat or control target temperature. 4 free surface (FS) Sn targets made of a TZM cup, illustrated in Figure 1 (a), were exposed in Nano-PSI to these 4 different plasmas, respectively, to explore liquid Sn surface behaviors. The cup was $2.5 \mathrm{~mm}$ deep, and the diameter for FS Sn was $22 \mathrm{~mm}$. To study the effect of CPS mesh on the droplet ejection from liquid Sn surface two different types of CPS Sn targets (CPS1 and CPS2) were applied in Nano-PSI, as seen in Figure 1 (b) and (c). The CPS1 target in Figure 1 (b) was assembled by adding a stack of molybdenum (Mo) meshes into the TZM cup of Figure 1 (a). The mesh pore size was $229 \mu \mathrm{m}$. The CPS2 target in Figure 1 (c) consisted of a wide TZM plate with a diameter of $60 \mathrm{~mm}$. There was a $5 \mathrm{~mm}$ wide and $2 \mathrm{~mm}$ deep well filled with $\mathrm{Sn}$ in the center of the plate. The well was covered by one layer of Mo mesh. Four different meshes with pore sizes of 104, 229, 439 and 800 $\mu \mathrm{m}$ were used in turn. The design of the wide plate was used to collect ejected droplets from the well. The radius and the number of droplets in the area around the mesh were measured by an optical microscope (Dino-lite Pro AM4113T). Due to the measurement limitation of the microscope and the plate roughness error, only droplets with radius bigger than $5 \mu \mathrm{m}$ were included. During exposures, a Phantom V12 fast visible camera was applied to monitor plasma-liquid Sn interaction at the surface and record ejected Sn droplets during exposure. It can operate at 6242 frames per second (fps) at full resolution $(1200 \times 1024$ pixels). A video camera was also used to make recordings at 24 frames per second. An emissivity-independent spectropyrometer (FAR SpectroPyrometer model FMPI) and K-type thermocouples attached to targets were used to measure temperature. The plasma exposure conditions for Sn targets in Nano-PSI are listed in Table 1. Before plasma exposures, all targets were pre-heated up to $800{ }^{\circ} \mathrm{C}$ by the heater with a background pressure $\sim 10^{-5} \mathrm{~Pa}$ to achieve good wetting of liquid Sn with cup or CPS mesh and then the targets were cooled down below Sn melting point.
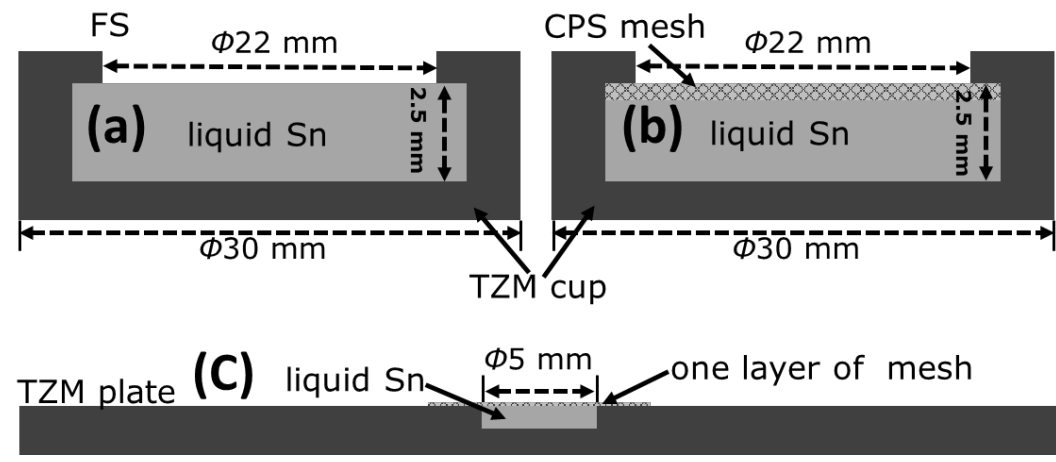

Figure 1 Sn targets exposed in Nano-PSI: (a) FS Sn target; (b) CPS Sn target (CPS1); (c) Sn target with one layer of mesh (CPS2) to explore droplet ejection. 
Magnum-PSI, in which plasmas are confined by the superconducting magnetic coils, is capable of realizing magnetic field as high as $\mathrm{B}_{\max } \sim 2.5 \mathrm{~T}$, and has the ability to achieve ITER-divertor relevant plasma fluxes. The CPS Sn target (CPS3) exposed in Magnum-PSI was the same as those described in [25]. A FLIR SC7000MB infrared camera was used to measure surface temperature and the same emissivity-independent spectropyrometer used in Nano-PSI was applied to cross-check the IR camera and determine the target surface emissivity. Table 2 displays the plasma exposure conditions for CPS3 Sn target in Magnum-PSI. During the exposure the target surface was monitored by the same visible fast camera (Phantom V12) viewing tangentially to the surface. The videos taken by the fast camera for both the Nano-PSI and Magnum-PSI exposures were analyzed by the APREX TRACK software [34] to detect and track multiple objects on videos. The minimum objective size that is detectable by the fast camera is close to $\sim 76 \mu \mathrm{m}$ in Nano-PSI and $\sim 337 \mu \mathrm{m}$ in Magnum-PSI. In Magnum-PSI, due to high electron density and temperature, therefore high heat fluxes, droplets are always heated to glow, being possibly accompanied with micro-vapor-cloud that can be excited and ionized. In this case, the droplets that are much smaller than $\sim 337 \mu \mathrm{m}$ can still be expected to be captured by the fast camera. On the other hand, in Nano-PSI, due to the very low plasma density and temperature, Sn droplets cannot be significantly heated and are not glowing. Thus, the minimum detectable droplet size is close to $\sim 76 \mu \mathrm{m}$.

Table 1 Plasma exposure conditions for Sn targets in Nano-PSI

\begin{tabular}{cccc}
\hline Sn targets & Ion species & Ion flux $\left(\mathrm{m}^{-2} \mathrm{~s}^{-1}\right)$ & Temperature $\left({ }^{\circ} \mathrm{C}\right)$ \\
\hline FS1 & & & \\
FS2 & $\mathrm{He}^{+}$ & $10^{20}-10^{21}$ & $200-800$ \\
FS3 & $\mathrm{Ar}^{+}$ & $10^{22}-10^{23}$ & $400-1100$ \\
FS4 & $\mathrm{H}_{3}{ }^{+}$ & $10^{19}-10^{20}$ & $200-700$ \\
\hline & $\mathrm{N}_{3}{ }^{+}$ & $\sim 10^{21}$ & $200-630$ \\
CPS1 & $\mathrm{H}_{3}^{+}$ & $3 \times 10^{20}$ & $\sim 400$ \\
& $\mathrm{~N}_{3}{ }^{+}$ & $\sim 10^{21}$ & $640-850$ \\
\hline CPS2 & $\mathrm{He}^{+}$ & $10^{20}-10^{21}$ & $350-820$ \\
\hline
\end{tabular}

Table 2 Plasma exposure conditions for CPS Sn in Magnum-PSI

\begin{tabular}{ccccc}
\hline Sn targets & $\begin{array}{c}\text { Ion } \\
\text { species }\end{array}$ & Ion flux $\left(\mathrm{m}^{-2} \mathrm{~s}^{-1}\right)$ & $\mathrm{B}(\mathrm{T})$ & Temperature $\left({ }^{\circ} \mathrm{C}\right)$ \\
\hline \multirow{3}{*}{ CPS3 } & $\mathrm{H}^{+}$ & $10^{23}$ & 0.4 & 700 \\
& $\mathrm{He}^{+}$ & $(1-8) \times 10^{23}$ & 0.4 & $600-1000$ \\
& $\mathrm{Ar}^{+}$ & $(1-5) \times 10^{23}$ & 0.4 & $200-600$ \\
\hline
\end{tabular}

\section{Results}

\subsection{Comparison of FS Sn targets among $\mathrm{Ar}, \mathrm{He}, \mathrm{H}$ and $\mathrm{N}$ plasma exposures}

\subsubsection{Argon and helium plasma exposures}

A FS Sn target (FS1) was first exposed to He plasma. The plasma flux was increased from $10^{20}$ to $10^{21} \mathrm{~m}^{-2} \mathrm{~s}^{-1} \mathrm{while}$ the temperature subsequently varied from 200 to $800{ }^{\circ} \mathrm{C}$. During this whole process no changes were observed at the liquid Sn surface and no droplet ejection was observed either by eye or cameras, indicating a stable liquid surface. Then another FS Sn target (FS2) was exposed to Ar plasma by scanning discharge current and gas flow, increasing from minimum flux $\left(\sim 10^{22} \mathrm{~m}^{-2} \mathrm{~s}^{-1}\right)$ to maximum flux $\left(\sim 3 \times 10^{23} \mathrm{~m}^{-2} \mathrm{~s}^{-1}\right)$ with temperature varying from 400 to $1100^{\circ} \mathrm{C}$. The behavior of the liquid $\mathrm{Sn}$ surface was the same as that previous He plasma exposure until the Ar plasma flux and surface temperature reached characteristic values of $\sim 10^{23} \mathrm{~m}^{-2} \mathrm{~s}^{-1}$ and $900-1000{ }^{\circ} \mathrm{C}$. At this point some droplets were observed to be ejected from the surface. Figure 2 shows the ejection process of a small droplet from liquid Sn FS exposed to Ar plasma at $\mathrm{T} \sim 1000{ }^{\circ} \mathrm{C}$ with $\sim 10^{23} \mathrm{~m}^{-2} \mathrm{~s}^{-1}$, captured by the fast camera with a frame rate of $1000 \mathrm{fps}$ (see Supplementary File 1). The time in the figure is the relative time to show the time evolution of droplet ejection and to make the droplet more visible it has been marked by a blue dot.

In the area of Figure 2 marked by a white circle from (a) $t=0 \mathrm{~ms}$ to (c) $\mathrm{t}=2 \mathrm{~ms}$, the formation of a small bubble can be observed. The diameter of the bubble was around $\sim 0.5 \mathrm{~mm}$. And then the bubble began to burst. Photo at (d) $t=3 \mathrm{~ms}$ recorded the bubble bursting and an ejected droplet can be observed at (e) $t=4 \mathrm{~ms}$ and (f) $t=5 \mathrm{~ms}$. This is a 
typical "jet" droplet, where the collapsing bubble forms a crater which then collapses, pushing up a central column which then breaks into droplets [35]. For most cases, the size of most bubbles is too small to be determined from the camera images. Droplet ejection density under such Ar plasma condition was quite low and estimated to be around $5 \sim 10$ counts/s and their ejection speed was in the range of $0.5 \sim 2 \mathrm{~m} / \mathrm{s}$. No clear droplets were observed when flux and temperature were below $\sim 10^{23} \mathrm{~m}^{-2} \mathrm{~s}^{-1}$ and $\sim 900^{\circ} \mathrm{C}$.

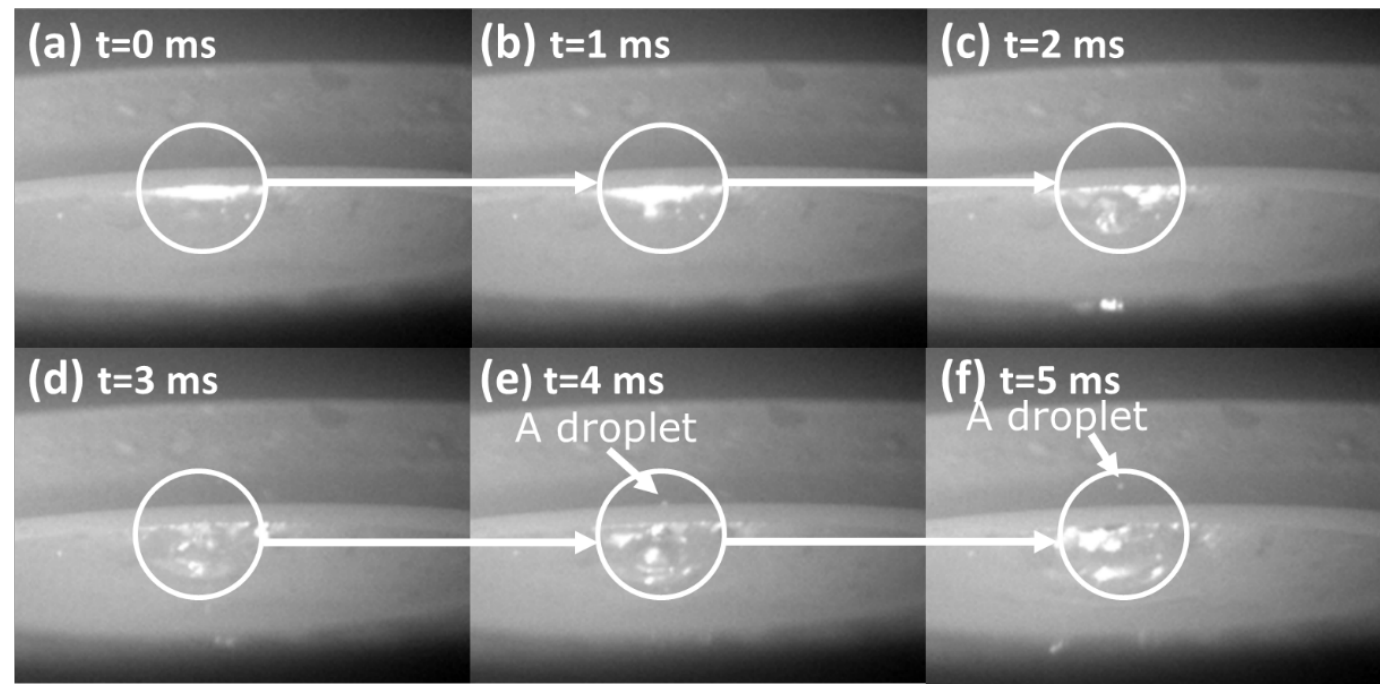

Figure 2 Ejection of a small droplet from FS liquid Sn (SF2) exposed to Ar plasma. A small bubble can be seen at (c) $t=2 \mathrm{~ms}$; the ejected droplet pointed out by an arrow can be found at (e) $t=4 \mathrm{~ms}$ and (f) $t=5 \mathrm{~ms}$ (The motion of the droplet can be seen in Supplementary File 1).

\subsubsection{Hydrogen and nitrogen plasma exposures}

The behaviors of liquid Sn FS in H and N plasmas were quite different from the exposures in Ar and He plasmas. Droplets can be immediately observed once Sn melted during H plasma exposure even at a quite low ion flux $(\sim$ $10^{19} \mathrm{~m}^{-2} \mathrm{~s}^{-1}$ ) and the number of droplets produced per second increases with ion flux and temperature. Figure 3 (a) shows the surface evolution of free surface liquid Sn during H plasma exposure taken by the fast camera at a frame rate of 1000 fps (also see Supplementary File 2). The ion flux and target equilibrium surface temperature were $3 \times 10^{20} \mathrm{~m}^{-2} \mathrm{~s}^{-1}$ and $\sim 685^{\circ} \mathrm{C}$. In Figure 3 (a), picture (i) to (iii) display the entire surface, in which in order to make droplets clearer and more readable and see their trajectories, 50 continuous frames were stacked into one picture using the image processing software ImageJ [36] .In the beginning of the exposure (at (i) $t=0 \mathrm{~s}$ in Figure 3 (a)), a very thin impurity layer possibly due to Sn oxide was floating on the liquid Sn surface. Around $0.1 \mathrm{~s}$ later, eruption of some sporadic tiny droplets began and the surface started to fluctuate, evolving into the slow break-up of the impurity layer. At t=1 s ((ii) in Figure 3 (a)), ejection of Sn droplets became apparent and the droplet trajectories can start to be seen. After $\sim 5 \mathrm{~s}$, the impurities totally disappeared (see picture (iii) in Figure 3 (a)). From $\mathrm{t}=5 \mathrm{~s}$ to the end of exposure, a large number of droplets were still ejected and their ejection rate appeared to be stable. Clear droplet trajectories can be found in the figure (iii) in Figure 3 (a). The formation and burst of bubbles that lead to droplet ejection have been observed. Photo (iv) in Figure 3 (a) shows one of these bubbles, which formed at $\mathrm{t}=20.394 \mathrm{~s}$. The size of the bubble was estimated to be $\sim 0.6 \mathrm{~mm}$ and it took about $1 \mathrm{~ms}$ before it can be seen through the camera. Several droplets were ejected out due to its bursting.

Surface evolution of FS Sn exposed to N plasma was presented in Figure 3 (b) (also see Supplementary File 3), in which (i) to (iii) are also the stack of 50 continuous frames to show the clear droplet trajectories, displaying the entire surface, and (iv) exhibits a quite big bubble at $\mathrm{t}=28.10667 \mathrm{~s}$. The ion flux and target temperature applied for $\mathrm{N}$ case was $\sim 2 \times 10^{21} \mathrm{~m}^{-2} \mathrm{~s}^{-1}$ and $460 \sim 620{ }^{\circ} \mathrm{C}$ and the frame rate of fast camera was $1200 \mathrm{fps}$. In Figure $3(\mathrm{~b}), \mathrm{t}=0$ $\mathrm{s}$ is the start of fast camera recording and plasma exposure began $60 \mathrm{~s}$ ago, namely at $\mathrm{t}=-60 \mathrm{~s}$. Similar behaviors of Sn surface were found compared with H plasma exposure: a skin of impurities, droplets starting to eject at a certain temperature, removal of impurities and appearance of lots of droplets until end of the exposure (as shown in Figure 3 (b)). However, there are some differences to be noted. Firstly, the skin of impurities was not shiny as that in $\mathrm{H}$ hydrogen, which indicates there should be something else formed on the surface during exposure which was suspected to be Sn nitride [37]. Secondly, no clear droplet ejection was captured by the camera during first 80 $\mathrm{s}$ (from $\mathrm{t}=-60 \mathrm{~s}$ to $\mathrm{t}=20 \mathrm{~s}$ ) until the temperature rose to around $\sim 600^{\circ} \mathrm{C}$, while for $\mathrm{H}$ plasma this behavior was 
observed above $\sim 232{ }^{\circ} \mathrm{C}$ (Sn melting point). Thirdly, the bubbles formed under $\mathrm{N}$ plasma can grow very big size $(1 \sim 10 \mathrm{~mm}$ ), as seen in picture (iv) in Figure $3(\mathrm{~b})$, and this normally occurred in the beginning of lots of droplet ejection. For the bubble in (iv), it almost took around $37.5 \mathrm{~ms}$ to grow up to its full size.
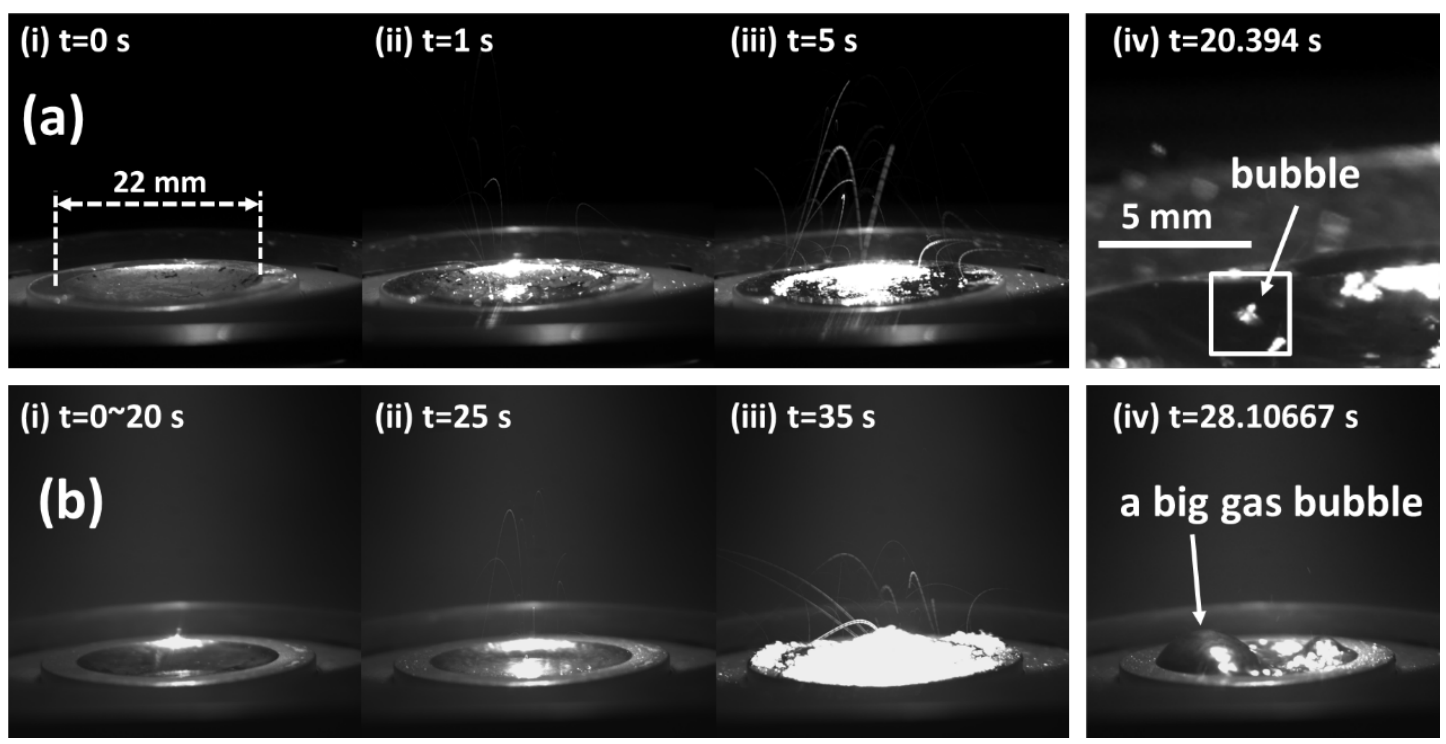

Figure 3 Time evolution of free liquid Sn surface exposed to $H(a)$ and $N(b)$ plasma, respectively. In (a), $t=0 \mathrm{~s}$ is the beginning of the exposure and also the start of fast camera recording; while, in (b) $t=0 \mathrm{~s}$ is just the start of the fast camera recording and the plasma exposure has begun around $60 \mathrm{~s}(t=-60 \mathrm{~s})$ before $t=0 \mathrm{~s}$.

Through analyzing these two videos from Figure 3 taken by the fast Phantom Camera with TRACK, the number of ejected Sn droplets as a function of time and their speed distribution can be acquired, which have been presented in Figure 4, in which (a) and (b) are the droplet ejection rate as a function of time for liquid FS Sn under $\mathrm{H}$ and $\mathrm{N}$ plasma, respectively; and (c) describe the distributions of maximum speed of these ejected Sn droplets. During $\mathrm{H}$ plasma exposure, the target temperature was kept at $\sim 685^{\circ} \mathrm{C}$ by the heater, while in $\mathrm{N}$ plasma exposure the target was pre-heated to $470^{\circ} \mathrm{C}$. The time-evolution of temperature can be also seen in Figure 4 (a) and (b).In Figure 4 (a) the droplet ejection rate under $\mathrm{H}$ plasma exposure slowly increases from 0 counts/s at the beginning of exposure to $\sim 800$ counts/s at $\sim 5 \mathrm{~s}$ and remains close to this value for the rest of the exposure. As shown in the Figure 3 (a), a layer of impurities existed on the surface before $5 \mathrm{~s}$, which likely helps explain the evolution of the droplet ejection rate. During exposure these impurities disappeared, presumably either attached on Sn droplets or sputtered or chemically etched by the plasma, and were completely depleted after $5 \mathrm{~s}$. For the case of N plasma in Figure 4 (b), there are not too many droplets before $\mathrm{t}=22 \mathrm{~s}$. After $22 \mathrm{~s}$ when temperature increases to around $\sim 615^{\circ} \mathrm{C}$, droplet ejection rate starts to increase and reaches around 800 counts/s at $\mathrm{t}=26 \mathrm{~s}$ and then drops until $\mathrm{t}=28 \mathrm{~s}$. After $28 \mathrm{~s}$, droplet ejection rate slightly increases again to $500 \sim 600$ counts/s. The break-up of the impurity layer in $\mathrm{N}$ plasma occurred at around $\mathrm{t}=26 \mathrm{~s}$, and could be responsible for the very high droplet ejection rate at this moment. 

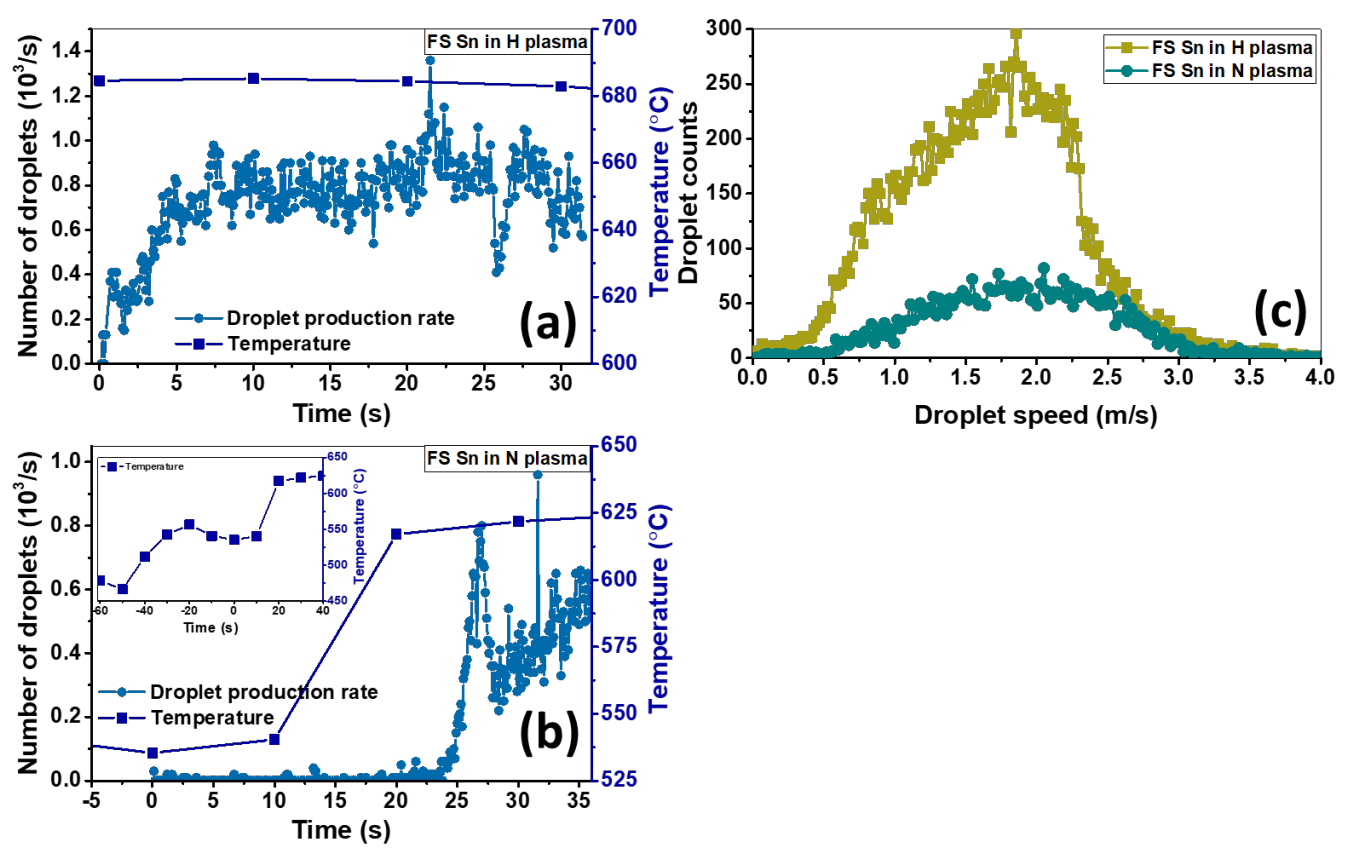

Figure 4 (a) and (b) are the number of ejected droplets from liquid FS Sn as a function of time for H plasma and N plasma, respectively. As indicated in Figure 3, $t=0 \mathrm{~s}$ is the beginning of the H exposure and also the start of the fast camera recording, while, for $N$ plasma, the beginning of the exposure is at $t=-60 \mathrm{~s}$ and the temperature evolution for the whole exposure is indicated in the inserted plot in Figure 4 (b). (c) shows droplet maximum distribution for $N$ and H plasma exposure.

The distributions of maximum speed displayed in Figure 4 (c) indicate that the speed of most droplets is in the range of $0.6 \sim 2.5 \mathrm{~m} / \mathrm{s}$ for hydrogen and $1.0 \sim 2.8 \mathrm{~m} / \mathrm{s}$ for nitrogen. The forces applied to droplets from plasma can be neglected due to low electron density and temperature, thus only gravity acts on the droplets. When a droplet was ejected up from the surface and fell down back to the surface the work from gravity was zero. Therefore, the maximum speed can be considered as droplet ejection speed. From Figure 4 (c), the median value of the maximum speed can be easily worked out, which is 1.67 and $1.87 \mathrm{~m} / \mathrm{s}$ for FS Sn in H and N plasma, respectively. This means the ejecting speed of $50 \%$ of droplets is below $1.67 \mathrm{~m} / \mathrm{s}$ for liquid $\mathrm{Sn}$ in $\mathrm{H}$ plasma.

\subsection{Droplet ejection from CPS liquid Sn target exposed to H and N plasma in Nano-PSI}

During plasma exposures of FS Sn, bubble formation and bursting were observed, resulting into droplet ejection. We next investigated if the application of CPS-based design could suppress bubble formation and avoid droplet ejection as CPS can provide a surface stabilization via the surface tension force with very small pore mesh. In order to investigate the behavior of CPS design, a CPS liquid Sn target (CPS1 in Figure 1 (b)) was exposed to different plasmas in Nano-PSI. Figure 5 shows its surface evolution under different exposures. Figure 5 (a) is the CPS1 target before H plasma exposure, in which a part of the CPS mesh in the center was not totally wetted as some bare mesh was presented. After the target was exposed to H plasma, the wetting was significantly improved. Manhard et al. also observed such hydrogen plasma-assisted wetting at low temperature in their experiment [38]. Figure 5 (b) and (c) display two pictures of $\mathrm{H}$ plasma exposure at $\sim 20 \mathrm{~s}$ and $\sim 120 \mathrm{~s}$, respectively. When $\mathrm{H}$ plasma exposure started, some liquid Sn slowly moved onto the surface and flowed out of mesh. This started from the rim of CPS mesh close to cup due to its relatively low position, and then spread toward the center. Around $120 \mathrm{~s}$ later, more liquid Sn has appeared on the mesh surface and formed a liquid Sn pool, as seen in Figure 5 (c) (see Supplementary File 4). Ejection of sporadic droplets still accompanied the whole process. After the exposure the target was naturally cooled and a solid Sn bulk was presented on the top of mesh in the cup as shown in the figure 5 (d). This CPS1 target was then exposed to He plasma and no droplets were observed. Meanwhile, the Sn sitting above the mesh gradually returned into the cup through the mesh and disappeared (Figure 5 (e)). Overall this behavior implies that during $\mathrm{H}$ plasma exposure there were some gas bubbles formed inside the cup and these bubbles pushed liquid Sn out of the CPS mesh. When the target was exposed to He plasma, the gas inside the bubbles escaped slowly throughout the mesh, allowing the mesh to return to its original shape and for the $\mathrm{Sn}$ to return inside the CPS.

The same behavior also happened during $\mathrm{N}$ plasma exposure of the same target. When the plasma was switched from He plasma to N plasma (from (e) to (f) in Figure 5 ), a pool of liquid $\mathrm{Sn}$ appeared again on the mesh surface 
but with fewer droplets compared with liquid Sn exposed to H plasma (Figure 5(c)). The target was then heated up to $850^{\circ} \mathrm{C}$ by the heater and the liquid $\mathrm{Sn}$ in the center area produced a very large number of small droplets (see Supplementary File 5). In the end, the plasma was switched back to He plasma (from (g) to (h)) and droplets disappeared. Liquid Sn again sank into the cup through the mesh, which also again returned to its original shape.

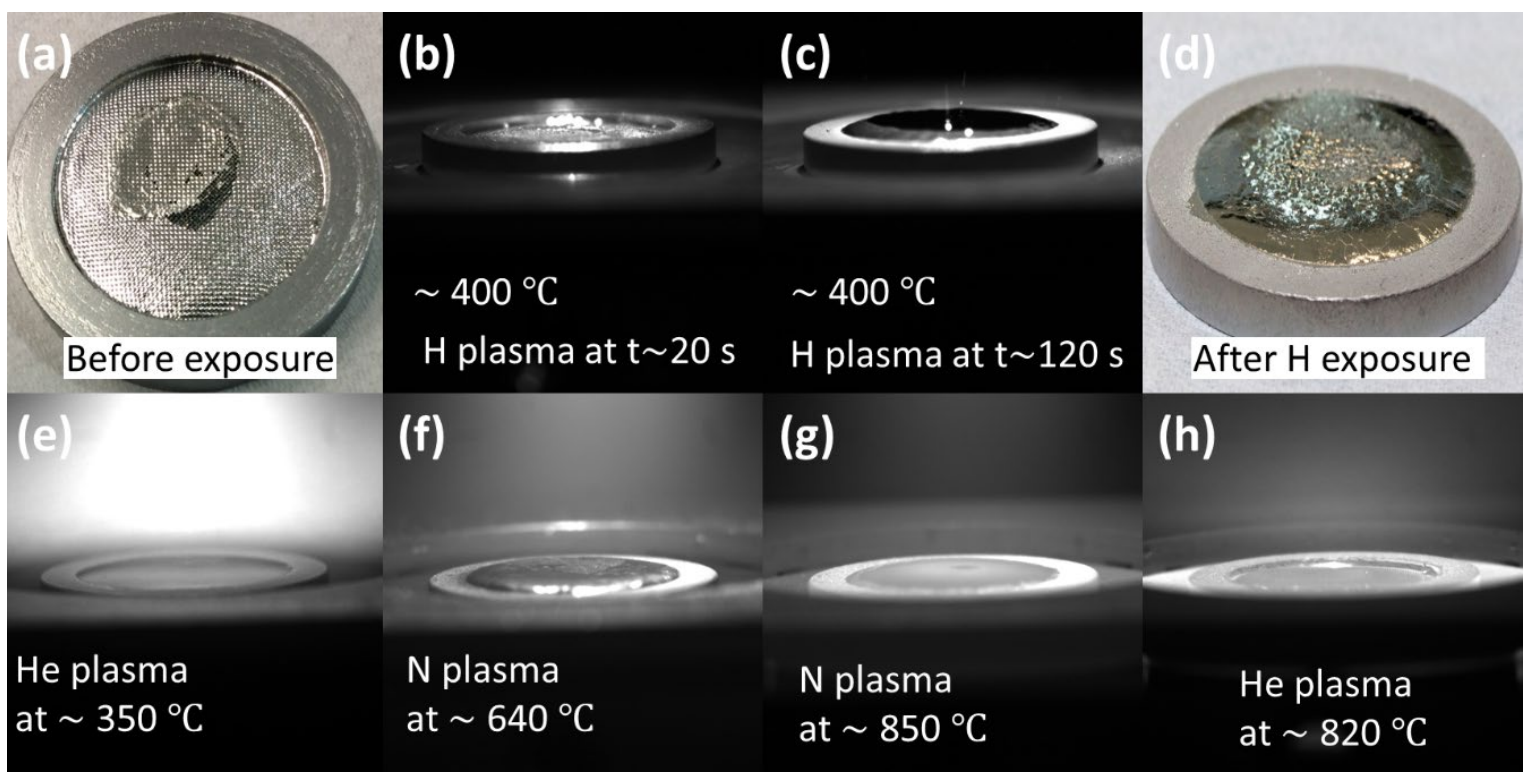

Figure 5 Surface evolution of CPS1 target exposed to H, He and N plasma, respectively in Nano-PSI. (a) a Sn-filled CPS1 target before exposure and the mesh was not totally wetted in the center; (b) the CPS1 target at $t=\sim 20 \mathrm{~s}$ during H exposure; (c) the CPS1 target at $t=\sim 120 \mathrm{~s}$ during H plasma exposure and a liquid Sn pool was presented above CPS mesh; (d) the photo of CPS1 target after H plasma exposure; (e) the same CPS1 target from (d) was again exposed to He plasma and the Sn pool has disappeared; (f) the CPS1 target was then exposed to N plasma at $640{ }^{\circ} \mathrm{C}$ and a Sn pool appeared again; (g) a photo of the CPS target under N plasma at $850^{\circ} \mathrm{C}$ with too many small bubbles formed and burst, see Supplementary File 5; (h) the target was in the end exposed to He plasma at $820^{\circ} \mathrm{C}$ and the $\mathrm{Sn}$ pool completely disappeared.

Bubbles were also found for the case of CPS liquid Sn exposed to H plasma as shown in Figure 6, in which a bubble with a diameter of $\sim 2 \mathrm{~mm}$ on the $\mathrm{Sn}$ pool of CPS Sn target was presented. Due to its relatively big size its bursting can be well presented, as seen from Figure 6 (a) to (1). This is a typical forming process of jet-droplet [39, 40]. At (a) $\mathrm{t}=0 \mathrm{~ms}$, the bubble was not presented, while after $1 \mathrm{~ms}$ later the bubble can be clearly observed at (b). At $\mathrm{t}=2 \mathrm{~ms}$ the bubble grew big until it started to burst at $\mathrm{t}=3 \mathrm{~ms}$, in which the top rim of the bubble started to break and a cavity was formed in the 'white spot' position. This bursting process lasted around $6 \mathrm{~ms}$ until $\mathrm{t}=9 \mathrm{~ms}$ when a jet droplet was ejected out as seen in (k) and (l).

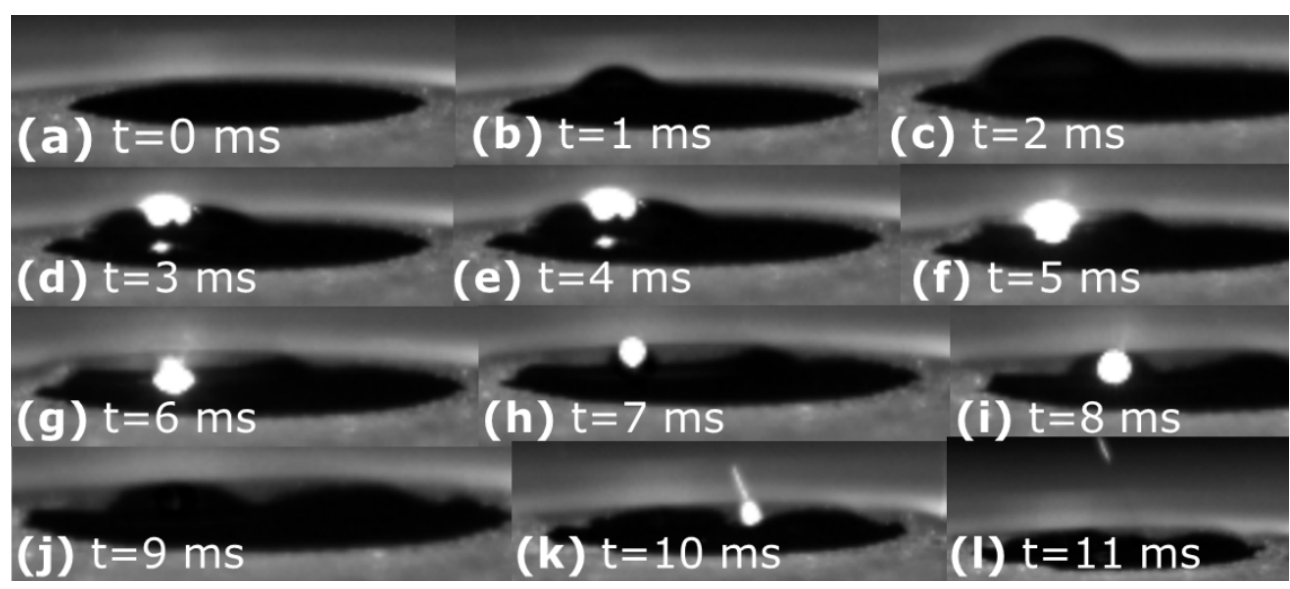

Figure 6 Formation and bursting of a big bubble in liquid Sn pool on the CPS mesh exposed to H hydrogen (the time in the figure is the relative time interval at frame rate $=1000 \mathrm{fps}$ and not the exposure time), see Figure 5 (c). 
Figure 7 shows photos of another CPS1 liquid Sn target exposed to hydrogen plasma taken by the video camera. Alternate expanding and shrinking of the mesh occurred due to the formation of a big gas bubble inside the cup. The cycle time from expanding to shrinking was about $1-2 \mathrm{~s}$. As the mesh was wetted by liquid $\mathrm{Sn}$, once the pressure inside the cup grew high (mesh expanding) the gas inside the cup was released via pushing liquid Sn out of the mesh (shrinking), shown in Figure 7 (e). If the mesh was well wetted, the gas pressure inside could be very high, and a sudden erupt of liquid Sn splash from mesh surface would occur, which has been indicated in Figure 7 (b). The edge of the mesh was found damaged after exposure as is later discussed in section 5 (Figure 15 (a)).

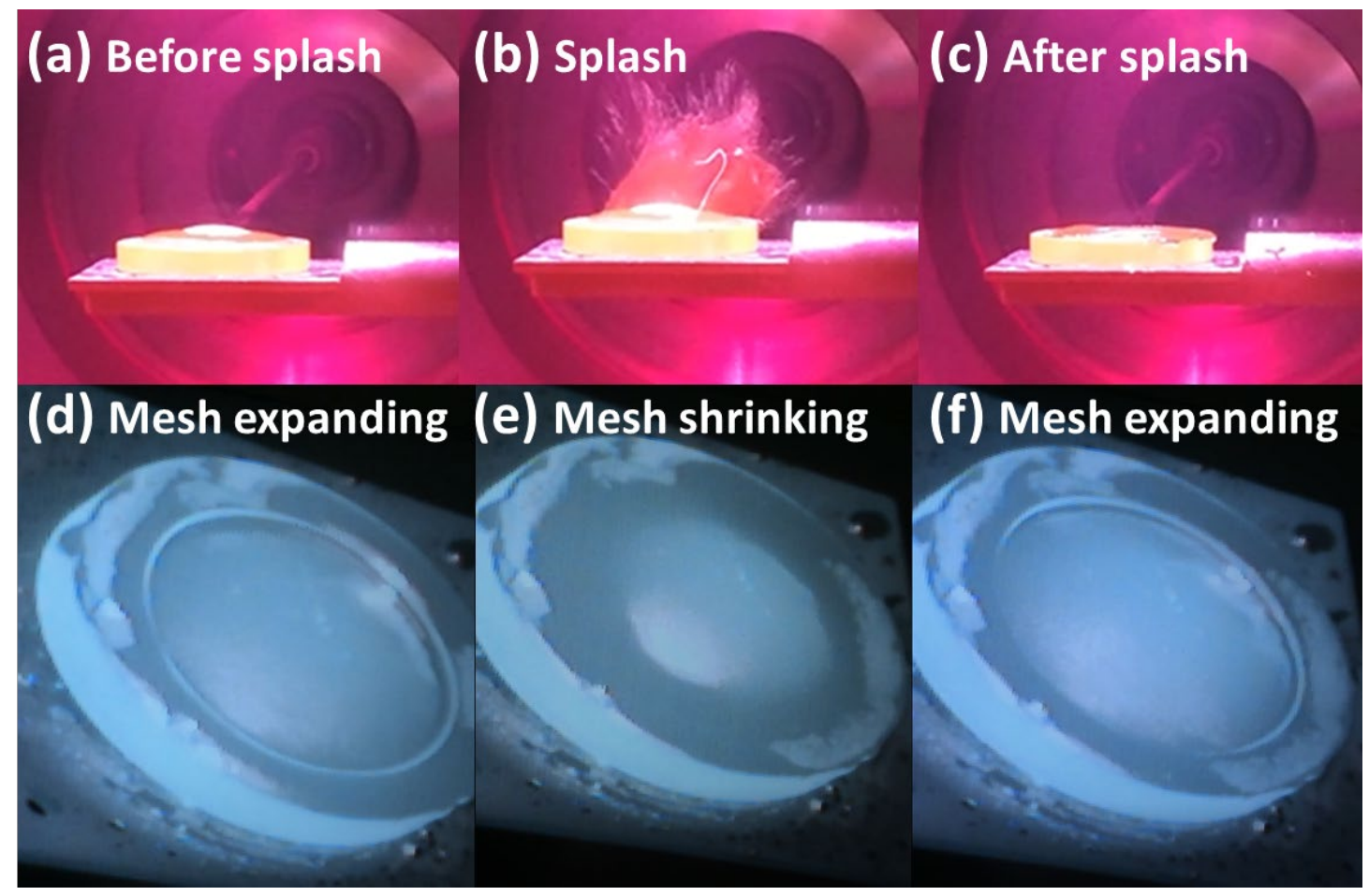

Figure 7 Alternate expanding and shrinking of CPS mesh and liquid Sn splash. (a) to (c): liquid Sn splash due to mesh expanding; (d) to (f): mesh expanding and shrinking due to the accumulation of hydrogen gas bubbles inside the cup.

Even through CPS mesh seems not to avoid droplet ejection, it indeed decreases droplet densities. However, it is unclear if the droplet production occurs due to the free-surface region in the centre, due to the collapse of the large bubble under the mesh, or due to small bubble bursting between the pores of the mesh. To understand the influence of mesh size on droplet ejection, meshes with different pore sizes were applied for $\mathrm{H}$ plasma case, as shown in Figure 8 (a), in which one layer of different mesh sizes was wetted by Sn (target CPS2, Figure 1 (c)). All CPS2 Sn targets were exposed to $\mathrm{H}$ plasma for 5 minutes under the same conditions (see Table 1). The CPS2 Sn targets shown in Figure 8 (a) with mesh pore size of 104 and $229 \mu \mathrm{m}$ were photographed before H plasma exposure and the other two CPS2 Sn targets with mesh pore size of 439 and $800 \mu \mathrm{m}$ were photographed after exposure. Some droplets can already be observed for the latter two cases. For all cases, droplets smaller than $5 \mu \mathrm{m}$ found on the plate were not determinable using optical microscopy and not included in the counting. But these small droplets exist in all cases and can be observed by using SEM. Figure 8 (b) provides two SEM pictures to make a comparison between big droplets and smaller droplets. The radius and counts of those droplets bigger than (including) $5 \mu \mathrm{m}$ for different meshes are presented in Figure 8 (c), which presents the droplet counts per $\mathrm{cm}^{2}$ at different mesh sizes as a function of droplet sizes. Due to the low ion density and temperature, which resulted into a low heat flux and a low ion energy $(<5 \mathrm{eV})$, the ablation of droplets as a result of evaporation and sputtering can be ignored by the time they fall onto the plate. Judging from Figure 8 (b), there is also no obvious plasma etching effect that happened to droplets. Therefore, such ablations did not play a role in the measurement of droplet size shown in Figure 8 (b). As the vast majority of droplets were located in the range of $\sim 15 \mathrm{~mm}$ from the edge of the Sn well, only droplets in this area were counted. Compared to this droplet-collected area, the area of the Sn well can be neglected, and it is also logical to assume that those droplets falling back onto the $\mathrm{Sn}$ well have similar distributions with the droplets falling onto the plate. Therefore, the droplets that fell back onto the Sn well do not significantly affect our following analysis. The results of Figure 8 (c) exhibit obvious suppression by mesh refinement on droplet densities and sizes, 
and Sn erosion rate. For the $104 \mu \mathrm{m}$ mesh, the size of all droplets was below $30 \mu \mathrm{m}$ and the count in the range of $20-30 \mu \mathrm{m}$ was one order of magnitude lower compared with other big pore size meshes and the count in the range $5-20 \mu \mathrm{m}$ was also lower. The wide $800 \mu \mathrm{m}$ mesh shows high droplet counts almost for each size range of droplets (from $5-10 \mu \mathrm{m}$ to $60-80 \mu \mathrm{m}$ ). Droplets with the size bigger than $\sim 80 \mu \mathrm{m}$ only existed in this case. When compared with the case of FS liquid Sn in Figure 3, the droplet radius for FS Sn can even reach $\sim 540 \mu \mathrm{m}$, while when CPS meshes were applied the size of droplets typically are significantly smaller. For instance, the size of biggest droplets using $800 \mu \mathrm{m}$ mesh are in the range of $120 \sim 140 \mu \mathrm{m}$. However, Figure 8 (b) also indicates that the droplet suppression by this wider pore mesh was not as strong as those small ones $(104 \sim 439 \mu \mathrm{m})$, which shows smaller size and lower densities of droplets. The inserted plot in Figure 8 (c) displays an estimation of Sn erosion rate, only taking droplets bigger than $5 \mu \mathrm{m}$ (including $5 \mu \mathrm{m}$ ) into account, which indicates that the erosion rate for the mesh with big pore size is much higher than that of the mesh with smaller pore size. Compared to big droplets, the contribution of these small droplets $(<5 \mu \mathrm{m})$ to the total erosion rate is estimated below $10 \%$. From these results, it implies that, on the one hand, droplets can always exist, but on the other hand, the smaller the mesh pore size, the smaller the droplets and the lower the droplet density, and thus less Sn erosion rate.

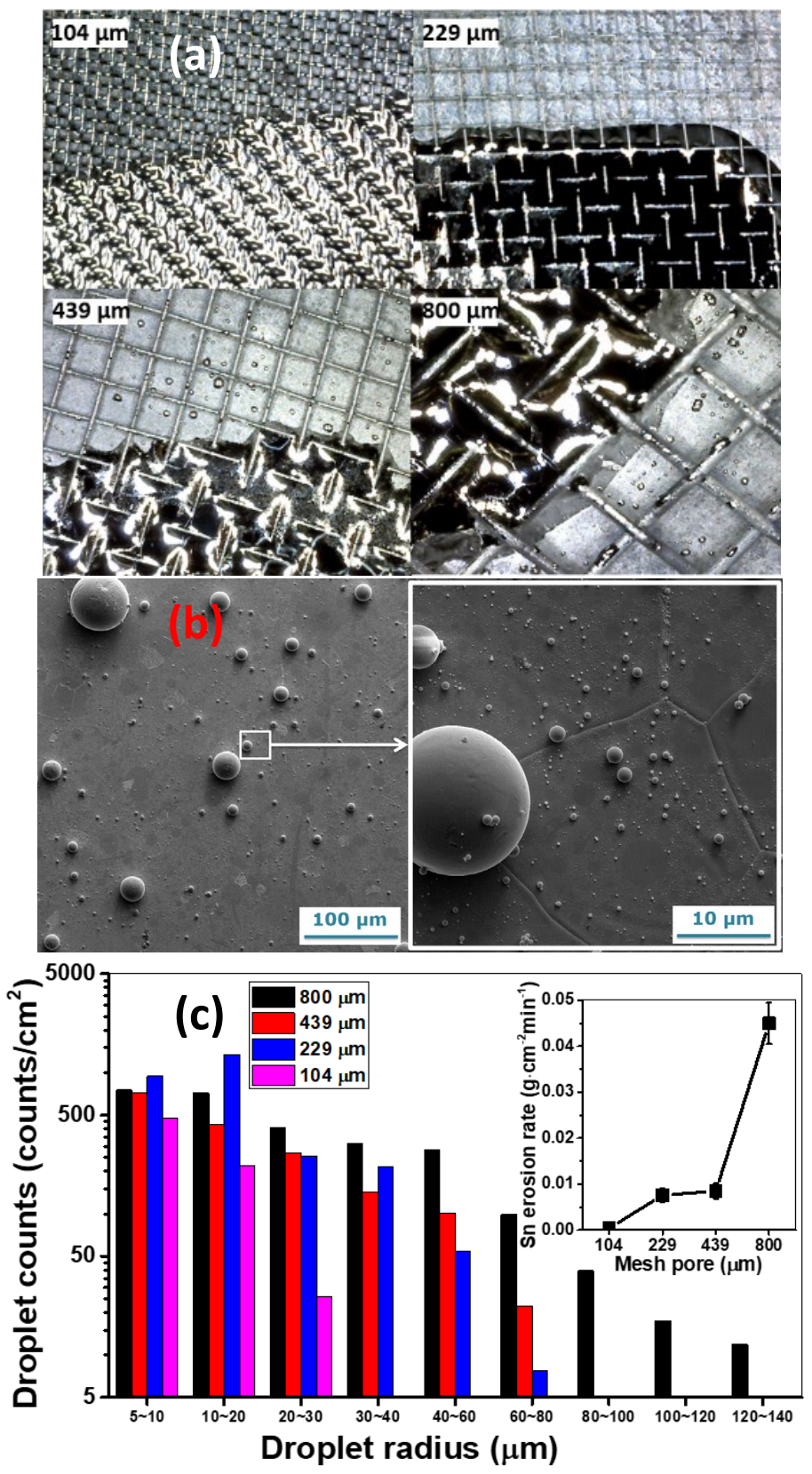


Figure 8 (a) CPS2 Sn target with the 104 and $229 \mu \mathrm{m}$ mesh before exposure and the 439 and $800 \mu \mathrm{m}$ mesh after exposure, respectively; (b) a SEM of Sn droplets and a zoom-in SEM of the white square area. (c) droplet counts per cm ${ }^{2}$ on the collection area for different meshes during 5 minutes of $H$ exposure time. The inserted plot displays an estimation of the Sn erosion rate from the Sn well, only taking droplets bigger than $5 \mu \mathrm{m}$ into account.

\subsection{CPS Sn sample exposed to plasmas in Magnum-PSI with magnetic field}

Droplets were not observed with liquid Sn being exposed to helium plasma in Nano-PSI, but were for argon plasma. One possible reason could be that unlike for argon, sufficiently high temperature $\left(\mathrm{T}>900-1000{ }^{\circ} \mathrm{C}\right)$ and a high plasma flux $\left(\sim 10^{23} \mathrm{~m}^{-2} \mathrm{~s}^{-1}\right)$ cannot be achieved with He plasma in Nano-PSI. In Magnum-PSI these conditions can be easily achieved and have been applied for the exposure of liquid CPS Sn (see Table 2). In this case it was found that $\mathrm{Sn}$ droplets can also eject out from the liquid Sn surface at high He plasma flux and high temperature. In Magnum-PSI the liquid CPS Sn targets were exposed to plasmas flowing horizontally (as opposed to vertically in Nano-PSI) with a magnetic field of 0.4 T. Figure 9 (a) and (c) show the exposures of CPS Sn to H and He plasma, respectively, in which the applied camera frame rate for both was 1500 fps. Each picture is again a stack of 50 continuous frames during the exposure and droplet trajectories can be seen clearly. (b) and (d) are a collection of droplet trajectories from 10000 frames (6.67s) analysed by TRACK. The plasma exposure conditions listed in Table 2 also included some other exposures to He plasma and Ar plasma. A very large number of droplets were presented for H plasma case (see Supplementary File 6) as shown in Figure 9 (a) and (b) even though the CPS meshes applied consisted of 3 layers of $104 \mu \mathrm{m}$ mesh. For the case of He plasma (see Supplementary File 7), only a few droplet trajectories were presented. Comparing Figure 9 (b) with (d), the density of ejected droplets in $\mathrm{H}$ plasma is much higher than that in He plasma. No droplets were observed for the case of Ar plasma in MagnumPSI when the conditions in Table 2 were applied.

It can be also seen that many ejected droplets follow curved trajectories back to the target holder area. It is well known that dust particles charge up very quickly inside plasmas and are then subjected to a large number of possible forces depending on size, charge and temperature [41]. Here most likely the ion drag force is dominant, hence driving most droplets to have curved trajectories back towards the target as the ions flow towards it. Outside the plasma column the trajectories appear straighter, which would be in agreement with the above statement as here the ion drag force should disappear. Via the analysis of these droplet trajectories with TRACK, it is found that $76 \%$ droplets returned back to the target in hydrogen plasma, while in the case of helium plasma, $80 \%$ were brought back to the target area. The remaining droplets either continued to move into the plasma, or were lost for tracking, for instance by escaping the focal plane of the camera.

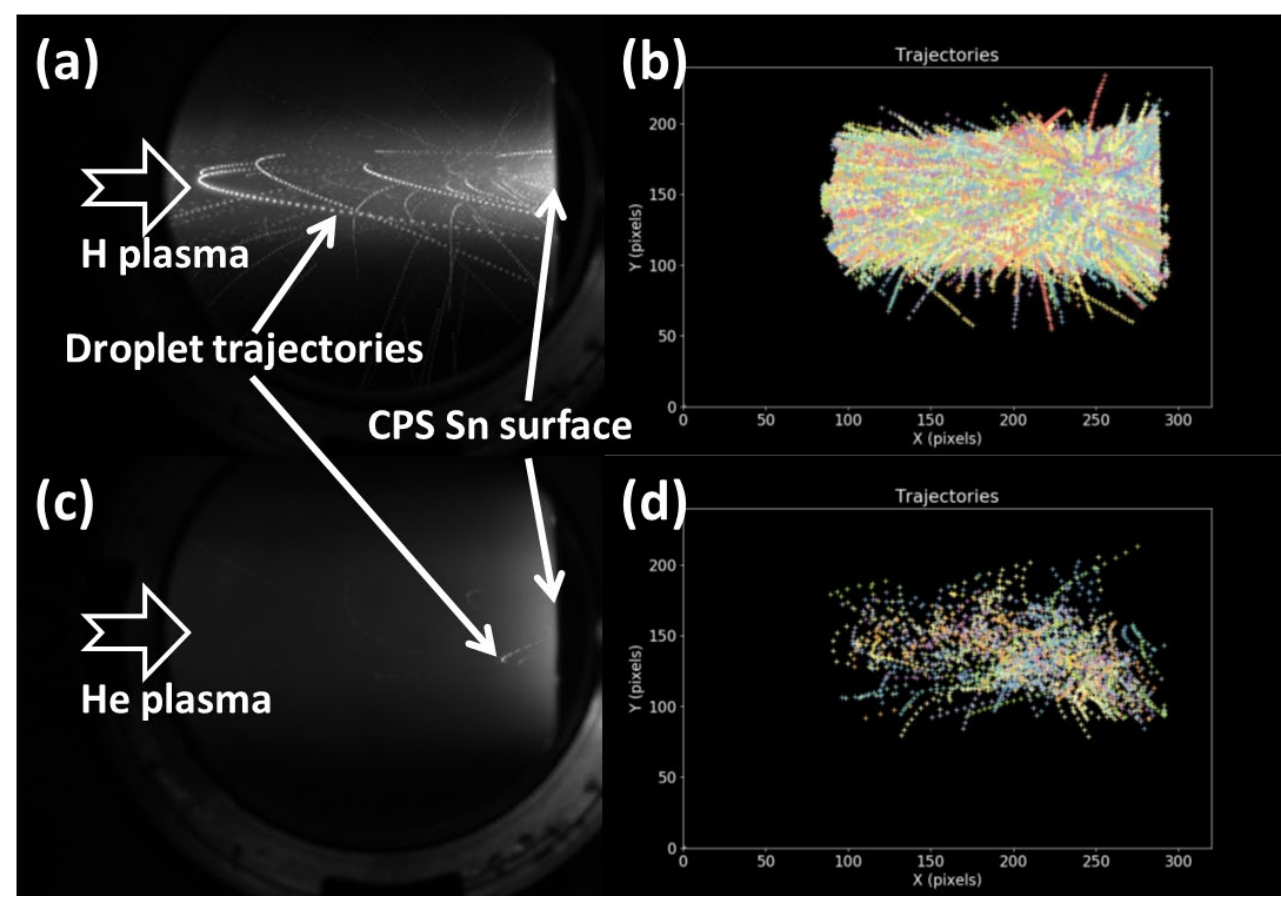

Figure 9 (a) (c) Liquid CPS Sn exposed to H and He plasma, respectively; (b) (d) a collection of droplet trajectories from continuous 10000 frames analyzed by TRACK for H and He plasma, respectively. 
The number of ejected droplets from liquid CPS Sn surface as a function of exposure time for $\mathrm{H}$ and He plasma cases determined using TRACK can be found in Figure 10 (a) and (b), in which the exposure temperature was also exhibited in the right axis. Although He plasma exposure was performed with higher flux and temperature, the droplet ejection rate is 6 to 7 times lower than that under $\mathrm{H}$ plasma, indicating an extremely unstable liquid $\mathrm{Sn}$ surface for the latter. The speed distribution of these ejected droplets is shown in Figure 10 (c). The maximum speed can be also considered as droplet ejection speed as the speed is typically highest as it leaves the surface. The peak of the distributions of the maximum speed for $\mathrm{H}$ case is around $2.2 \mathrm{~m} / \mathrm{s}$ while for the case of He plasma, several small peaks can be found from $0.5 \sim 3.0 \mathrm{~m} / \mathrm{s}$. From Figure 10 (c), it can be also figured out that the median value of maximum speed of droplets for $\mathrm{H}$ plasm is around $2.60 \mathrm{~m} / \mathrm{s}$ and $1.20 \mathrm{~m} / \mathrm{s}$ for He plasma. Figure 10 (b) and (d) are the angular distributions of the droplets ejected from CPS Sn surface in H and He plasmas, respectively. The angle is respected to the target surface with $0^{\circ}$ and $180^{\circ}$ corresponding to droplets that moved parallel to the target surface $\left(0^{\circ}=\right.$ top, $180^{\circ}=$ bottom $)$. In $\mathrm{H}$ plasma, the angular distribution is almost symmetrical with slightly more droplets below the horizontal axis. While, in the case of He plasma, the distribution is highly asymmetric with a large majority of droplets returning with significant curvature below the horizontal axis. No obvious droplets were observed for He plasma exposure at temperature below $800-900{ }^{\circ} \mathrm{C}$ in Magnum-PSI.
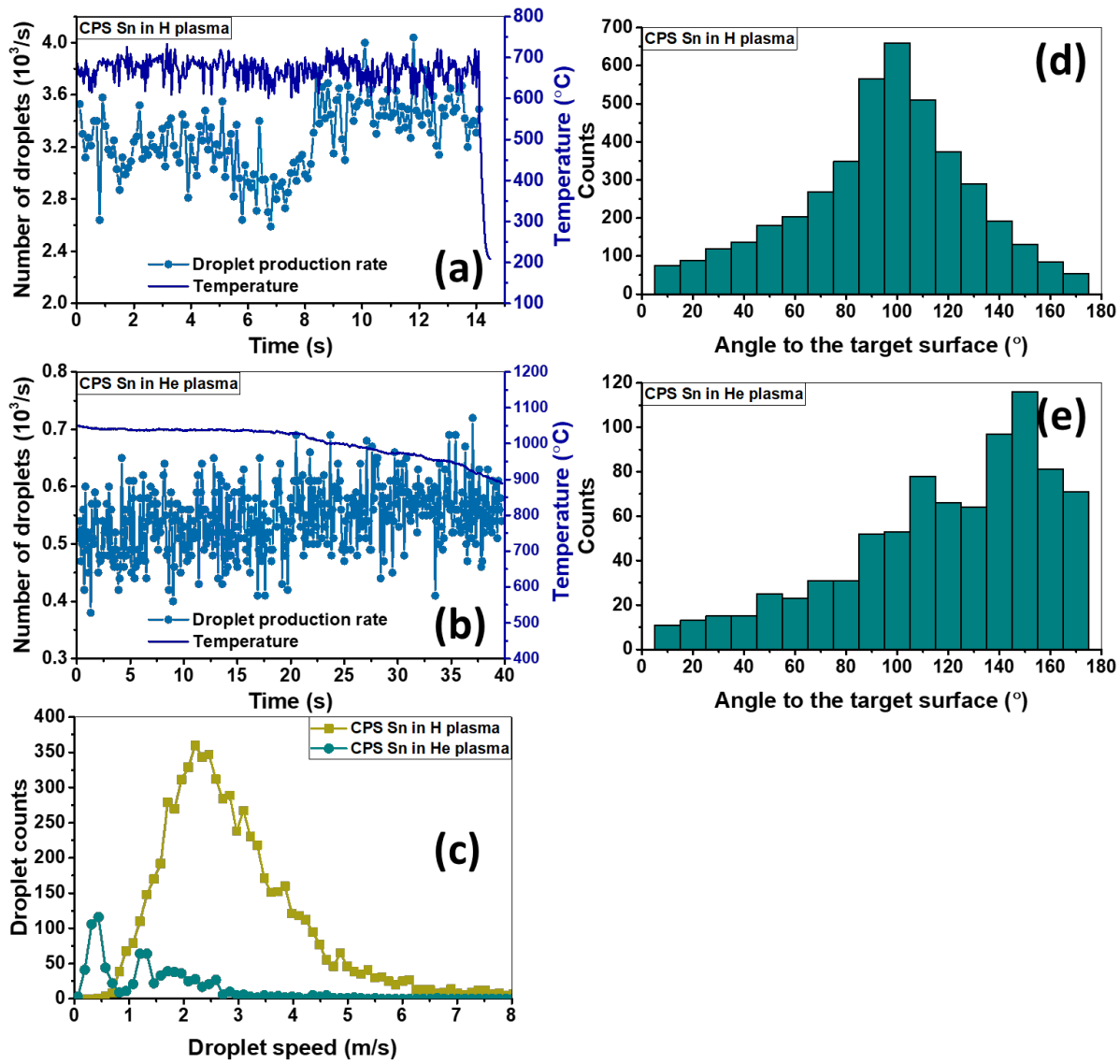

Figure 10 (a) (b) are droplet production rate as a function of exposure time for CPS Sn exposed to H plasma and He plasma, respectively, in Magnum-PSI; (c) are the droplet maximum speed distributions; (d) and (e) display the statistical analysis of the droplet angular distributions in $H$ and He plasmas.

\section{Mechanisms for bubble formation and growth}

Bubble formation has been confirmed by fast camera and proposed to be responsible for droplet ejection for $\mathrm{H} / \mathrm{N} / \mathrm{Ar} / \mathrm{He}$ plasmas in this experiment. However, the mechanism for bubble formation is still unclear and will be explored in this section. In first part, we will introduce 'plasma-enhanced solubility' [42], which is that the solubility of diatomic gas in liquid metals can be enhanced due to exposure to atomic plasma, such as $\mathrm{H}^{+}$and $\mathrm{N}^{+}$, and deduce possible enhanced solubility of hydrogen in liquid Sn under H plasma circumstances. Such enhanced solubility, as well as high implantation of plasma, could lead to a high supersaturation compared with normal solubility. The second part will describe the formation and growth of bubbles in supersaturated liquid Sn. The chemical reaction of hydrogen and nitrogen plasma with $\mathrm{Sn}$ will be explored in last part of this section, in which 
volatile $\mathrm{Sn}$ hydride and nitride, namely $\mathrm{SnH}_{4}$ and $\mathrm{Sn}_{3} \mathrm{~N}_{4}$, can be formed. The appearance of such volatile metastable gas could also inflence the surface behavior of liquid $\mathrm{Sn}$.

\subsection{Supersaturation of hydrogen in liquid Sn by hydrogen plasma exposure}

Supersaturation of gases occurs when the concentration of a gas in a liquid exceeds the solubility limit. The significant enhancement of solubility of diatomic molecule gas in liquid metals due to the presence of plasma has been stated and verified in [42-45]. Such so-called 'plasma-enhanced solubility' is much higher than normal solubility predicted by Sievert's Law. Deuterium present in the Sn was already found in our experiment to be much higher than predicted from Sievert's Law [25]. According to Sievert's Law solubility normally increases with temperature for endothermic dissolution and this is the case for hydrogen dissolved in liquid Sn [46]. However, the plasma-enhanced solubility has been found to decrease with temperature for hydrogen [43] and nitrogen [45] in liquid iron. Here we discuss the case of hydrogen, as there is no data available for nitrogen. However, a similar case can be argued. In the case of liquid Sn exposed to hydrogen molecule gas, the equilibrium reaction is given by

$$
1 / 2 H_{2(g)} \leftrightarrow[H]_{S n}
$$

The equilibrium constant for the reaction is

$$
K=\frac{A_{[H]}}{\sqrt{A_{H 2}}}=e^{-\frac{\Delta G_{H_{2}}^{0}}{R g^{T}}}
$$

Where $A_{[H]}=\gamma x_{H}$ is the thermodynamic activity of dissolved $\mathrm{H}$ atoms in the liquid $\mathrm{Sn}$ and $\gamma$ is the activity coefficient; $x_{H}$ is $\mathrm{H}$ mole fraction in liquid $\mathrm{Sn} ; A_{\mathrm{H} 2}=P_{\mathrm{H} 2} / P^{\Theta}$ is the activity of $\mathrm{H}_{2}$ gas and $P^{\Theta}$ is the Standard Pressure; $R_{g}$ is the ideal gas constant and $\mathrm{T}$ is temperature in Kelvin; $\Delta G_{\mathrm{H}_{2}}^{0}$ is the standard Gibbs free energy change of the reaction hydrogen molecule gas dissolving in liquid Sn. Some experimental data of hydrogen solubility in liquid Sn can be found in the literatures [47-49]. Among these data, Bever's are more reliable as already discussed in [25]. For dilute solvent, $\gamma$ approaches unity and this is the case of $\mathrm{H}$ dissolution in liquid $\mathrm{Sn}$. Through fitting his data, we can estimate the standard Gibbs energy change of the reaction Eq. (1) as

$$
\Delta G_{H_{2}}^{0}=1.23 \times 10^{5}+6.26 \cdot T \quad \mathrm{~J} \cdot \mathrm{mole}^{-1}(3)
$$

In our experiments there are three sources of hydrogen which can influence the concentration of hydrogen present in the tin. These are

1. $\mathrm{H}_{2}$ gas molecules, as stated above. These contribute to the equilibrium solubility limit as this process limits how the hydrogen atoms leave the surface.

2. $\mathrm{H}^{+}$(and $\mathrm{H}_{2}{ }^{+}$and $\mathrm{H}_{3}{ }^{+}$) ions from the plasma. These can implant directly below the surface, typically at a depth of $\sim 0.9 \mathrm{~nm}$ with $5 \mathrm{eV} \mathrm{H}^{+}$according to TRIM calculation. Following the logic in Manhard et al. using Fick's law [38], we assume that for the liquid $\mathrm{Sn}$ in steady state the implantation flux $\Gamma_{i m p l}$ and the re-emission flux back to the surface are approximately equal and are much larger than the permeation flux $\Gamma_{\text {perm }}$, and therefore the implantation concentration $c_{i m p l}$ at the average implantation depth $r_{i m p l}$ is given by

$$
c_{i m p l} \approx \frac{\Gamma_{i m p l} \cdot r_{i m p l}}{N_{A} D}\left(\text { mole } \mathrm{m}^{-3}\right)
$$

where $D$ is Fick's diffusion constant and as discussed in [25] can be taken as:

$$
D=2.33 \times 10^{-7} \exp \left(-\frac{11980}{R_{g} T}\right)\left(\mathrm{m}^{2} \mathrm{~s}^{-1}\right)(5)
$$

At equilibrium $\Gamma_{\text {perm }}=0$ and so $c_{i m p l}$ will be constant at this value throughout the bulk Sn.

3. H atoms (radicals), which can be generated by a variety of mechanisms such as dissociation of molecules, and recombination of ions in the plasma. These may enter directly into the Sn without dissociation. The dissolution reaction of such $\mathrm{H}$ atoms in liquid $\mathrm{Sn}$ can be given by

$$
H_{(g)} \leftrightarrow[H]_{S n}(6)
$$

The equilibrium constant for dissolution reaction Eq. (6) is also given by 


$$
K=\frac{A_{[H]}}{A_{H}}=e^{-\frac{\Delta G_{H}^{0}}{R g T}}(7)
$$

Where $A_{H} \approx P_{H} / P^{\Theta}$ is the activity of $\mathrm{H}$ atom gas and $P_{H}$ is $\mathrm{H}$ atom pressure. $\Delta G_{H}^{0}$ is the standard Gibbs free energy change of the reaction hydrogen atom gas dissolving in liquid Sn. The deduction of Gibbs energy for hydrogen atoms dissolved in liquid $\mathrm{Sn}$ can be found in appendix A, which is:

$$
\Delta G^{0}{ }_{H}=55.6 \cdot T-9.5 \times 10^{4} \mathrm{~J} \cdot \mathrm{mol}^{-1}(8)
$$

We still take $\gamma=1$, thus the dissolved H mole fraction in liquid Sn for Eq. (6) can be expressed as follows

$$
x_{H}=\frac{P_{H}}{P^{\Theta}} \cdot e^{-\frac{\Delta G_{H}^{0}}{R_{g} T}}
$$

Equilibrium constant for the reaction Eq. (1) and Eq. (6) as a function of temperature is given in Figure 11 (a), in which the dissolved $\mathrm{H}$ mole fraction in liquid $\mathrm{Sn}$ exposed to $\mathrm{H}_{2}$ molecule gas $\left(\mathrm{P}_{\mathrm{H} 2}=120 \mathrm{~Pa}\right)$ and $\mathrm{H}$ atom gas $\left(\mathrm{P}_{\mathrm{H}}=1\right.$ $\mathrm{Pa}$ ), respectively, as a function of temperature is also plotted. The former corresponds to the case of hydrogen solubility limit according to Sievert's Law, while the latter corresponds to 'plasma-enhanced solubility' in Nano$\mathrm{PSI}$ at $\mathrm{H}$ atom pressure $\sim 1 \mathrm{~Pa}$. Figure 11 (a) shows that equilibrium constant for the reaction (1) and the $\mathrm{H}$ solubility in liquid $\mathrm{Sn}$ in $\mathrm{H}_{2}$ gas increases with temperature, while equilibrium constant for the reaction (6) is much higher than that for the reaction (1) and has an inverse dependence on temperature. These are in agreement with literatures $[42][43][45]$ and with our experiments [25].

Here we define supersaturation ratio $\xi$ by the ratio of total concentration to the normal solubility limit, namely

$$
\xi=\frac{c}{c_{0}}(10)
$$

Where $c$ is the sum of plasma-enhanced solubility $c_{p e}\left(c_{p e}=n \cdot x_{H}, n\right.$ is number density of liquid Sn), ion implantation concentration $c_{i m p l}$ and normal solubility $c_{0}$. Figure 11 (b) displays an estimation of $c_{p e}, c_{i m p l}$ and $c_{0}$ as a function of temperature from above discussion in Magnum-PSI, in which we assume both $\mathrm{H}$ atom and $\mathrm{H}_{2}$ molecule pressures are equal to plasma pressure above liquid Sn surface. Hydrogen ion flux and plasma pressure in this experiment were about $\sim 10^{23} \mathrm{~m}^{-2} \mathrm{~s}^{-1}$ and $10 \mathrm{~Pa}$. The corresponding supersaturation ratio $\xi$ from Eq. (10) is also plotted in Figure 11 (b) and the supersaturation $\xi$ for Nano-PSI estimated from Figure 11 (a) is added as well. For the latter, the plasma ion implantation concentration has been neglected due to low ion flux.

It should be noted that the plasma-enhanced solubility from Eq. (9) could be the maximum dynamic H solubility once the equilibrium between $\mathrm{H}$ plasma and liquid $\mathrm{Sn}$ is built. However, it is suggested that once a certain supersaturation ratio and a certain concentration is achieved, the dissolved atoms can desorb from the supersaturated melt and form bubbles, thus the supersaturation ratio in Figure 11 (b) can be considered as the upper bound. 

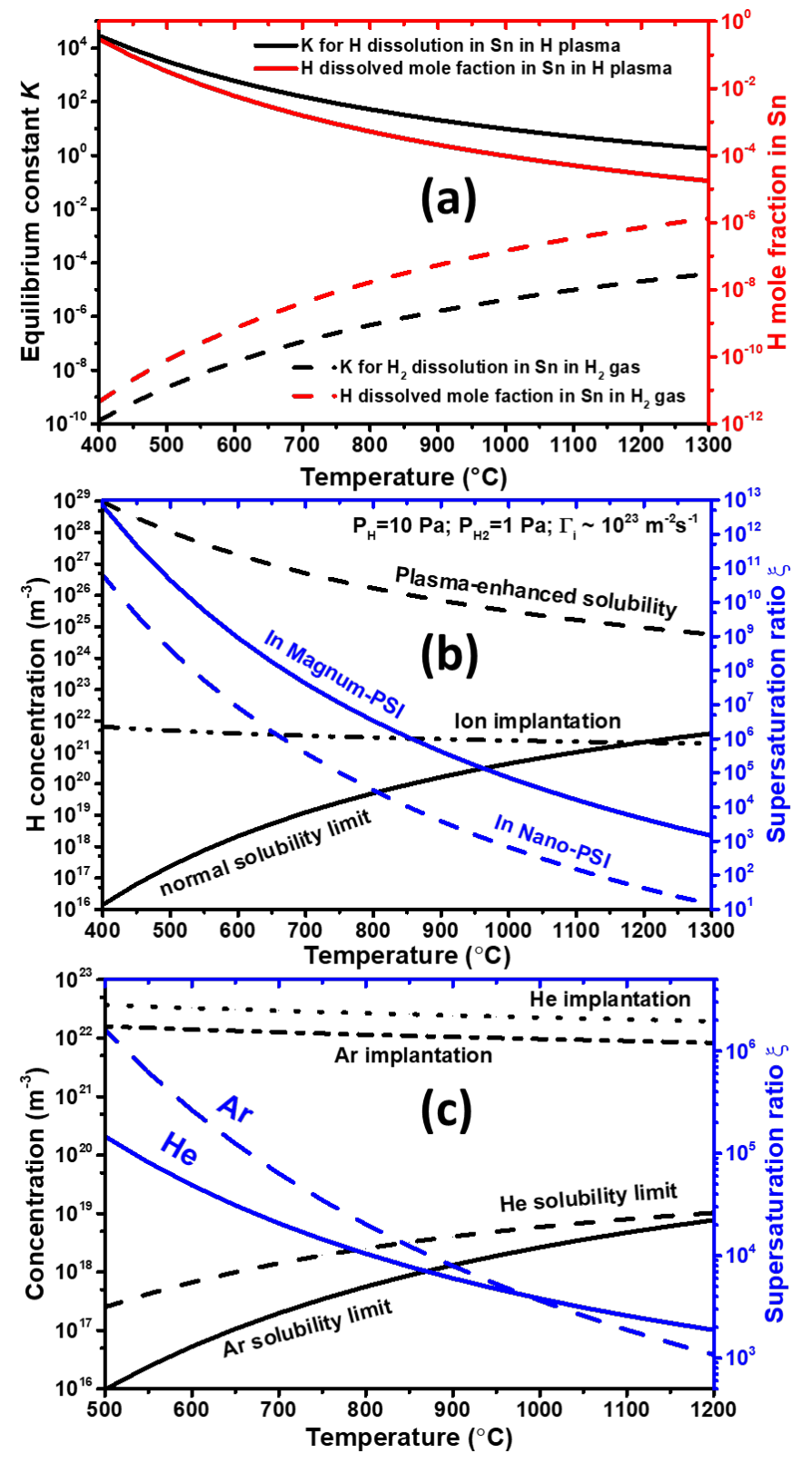

Figure 11 (a) Equilibrium constant and $H$ mole fraction in liquid $S n$ as a function of temperature in Nano-PSI $\left(P_{\mathrm{H}_{2}} \sim 120 \mathrm{~Pa}, P_{\mathrm{H}} \sim 1 \mathrm{~Pa}\right)$. Black solid and dash lines are for $\mathrm{H}_{2}$ gas and $\mathrm{H}$ atom dissolution process in liquid Sn, respectively. Red solid and dash lines are for normal solubility and plasm-enhanced solubility, respectively. (b) plasma-enhanced solubility $c_{p e}$, plasma ion implantation $c_{i m p l}$ and normal solubility $c_{0}$ as a function of temperature at $P_{H}=P_{H 2}=10 P a$ with the ion flux $\sim 10^{23} \mathrm{~m}^{-2} \mathrm{~s}^{-1}$ in Magnum-PSI. The supersaturation ratios in both Nano-PSI and Magnum-PSI are also added in the figure. (c) normal solubility, ion implantation concentration and supersaturation ratio of He/Ar in liquid Sn as a function of temperature at $P_{A r}=80 \mathrm{~Pa}, \Gamma_{i: A r} \sim 3 \times 10^{23} \mathrm{~m}^{-2} \mathrm{~s}^{-1}$ and $P_{\mathrm{He}}=65 \mathrm{~Pa}, \Gamma_{i: \mathrm{He}} \sim 8 \times 10^{23} \mathrm{~m}^{-2} \mathrm{~s}^{-1}$.

As for the case of liquid Sn exposed to monoatomic molecule plasma, such as Ar or He plasma, a supersaturated liquid Sn could be achieved by high ion implantation. As no experimental data of Ar or He solubility and diffusion in liquid Sn are available, we can just get some rough estimation from some theoretically predicted values. A predication of Ar and He solubility in liquid Sn can be found in [50], which can be expressed as below:

$$
\begin{gathered}
c_{A r}=1.5 \times 10^{-6} \cdot P T^{-\frac{5}{2}} e^{14-\frac{13471}{T}} \mathrm{Ar} / \mathrm{Sn}(11) \\
c_{H e}=4.8 \times 10^{-5} \cdot P T^{-\frac{5}{2}} e^{8-\frac{8660}{T}} \mathrm{He} / \mathrm{Sn} \text { (12) }
\end{gathered}
$$

Were $P$ is gas pressure in $\mathrm{Pa}$ and $T$ is temperature in $\mathrm{K}$. 
Ar and He diffusion coefficient can be estimated from the Stokes-Einstein equation:

$$
D=\frac{k T}{6 \pi \eta r}(13)
$$

where $k$ is Boltzmann constant, $T$ is temperature in $\mathrm{K}, \eta$ is viscosity and $r$ is the radius of the diffusing atom.

We still use Eq. (4) to estimate $\mathrm{Ar} / \mathrm{He}$ concentration in liquid Sn due to plasma implantation applying typical plasma condition in our experiment and assuming impact ion energy is $5 \mathrm{eV}$. Using TRIM simulation, the mean implantation range of $\mathrm{Ar}$ and $\mathrm{He}$ in tin is about 0.3 and $0.6 \mathrm{~nm}$, respectively. Assuming $\mathrm{Ar} / \mathrm{He}$ gas pressure above liquid Sn surface is equal to plasma pressure, then we can estimate the supersaturation ration as a function of temperature for liquid Sn exposed to Ar and He plasma, which is shown in Figure 11 (c). In the figure the solubility determined from Eq. (11) and (12) and the concentration due to plasma implantation are also displayed. The figure indicates that lower temperature results into higher supersaturation ratio due to very low solubility at low temperature, while the ion implantation concentration doesn't vary significantly with temperature.

\subsection{Bubble formation and growth in supersaturated liquid}

Once a sufficient supersaturation is achieved above the Sievert's or Henry's Law solubility limits these dissolved atoms can be desorbed and expelled out of the liquid in the form of bubbles [42, 45]. Such behaviors of bubble formation have been observed in [51,52]. As presented in section 3.1 and 3.2, we also observed many bubbles in the cases of exposure of liquid Sn to hydrogen and nitrogen plasmas. With the growth of bubbles, these bubbles would rise up to the surface and burst, resulting into droplet ejection as observed in the experiments. The forming process of a bubble proceeds in two steps 1 ) nucleation of a micro-critical bubble with critical radius $R_{c} ; 2$ ) growth of this micro-bubble into a macro-bubble. Nucleation is prerequisite for the formation and growth of bubbles, which results into the formation of a micro-bubble. In general, there are four types of nucleation in liquids [53][54], namely

- Homogeneous nucleation, which needs to overcome high energy barrier and requires high supersaturation level.

- Heterogeneous nucleation, which has relatively low energy barrier compared with homogeneous nucleation and requires low supersaturation level.

- Pseudo-classical nucleation, which requires pre-existing gas cavities with radius smaller than critical radius and has lowest energy barrier.

- Non-classical nucleation, which requires pre-existing gas cavities with bigger radius than critical radius and doesn't have energy barrier.

Investigation of nucleation in liquid Sn exposed to plasma is extremely complicated and out of this work. Here we only focus on the bubble growth once the nucleation has achieved and resulted into a critical bubble with critical radius $R_{c}$. According to Shi's simulation [39], the range of the jet-droplet radii is around $2-20 \%$ of the initial bubble radius. If this is the case for some droplets observed in our experiment, $0.1 \mu \mathrm{m}$-scale droplets shown in Figure 8 (b) would correspond to bubbles with radius of $0.5-5 \mu \mathrm{m}$, which indicates that the upper bound of the critical radius of some bubbles should be smaller than this size. In [40], Duchemin also simulated the bubble bursting process and concluded that the radius of the first droplet due to jet formation is about $10 \%$ of the initial bubbles radius. In [25], the pits in the range of $0.1-1 \mu \mathrm{m}$ are observed on Sn surface after exposure. $1 \mu \mathrm{m}$-scaled bubbles in liquid Sn exposed to hydrogen plasma are also reported by Ruzic [28]. Taking all of these into account, it is logical to assume the critical radius for a nucleated micro-bubble is on the level of $0.1-1 \mu \mathrm{m}$. Some models for bubble growth in supersaturated or superheated liquid can be found in $[55,56,39]$. Here we take an approach that is similar with G. Yu. Gor's [57] to give a bubble growth model assuming that the gas in the bubbles obeys the ideal gas law:

$$
P V=N k T(14)
$$

where $P$ is gas pressure in the bubble, $V=\frac{4 \pi}{3} R^{3}$ is the bubble volume, $N$ is the number of molecules in the bubble and $k$ is Boltzmann constant.

Using Laplace pressure, the bubble gas pressure can be written as

$$
P=P_{l}+\frac{2 \sigma}{R}(15)
$$


where $P_{l}$ is the ambient pressure and assumed to be gas pressure or plasma pressure. Here we ignore liquid pressure and only take bubble formation in top liquid layer into account; $\sigma$ is the liquid Sn surface tension and $R$ is bubble radius. The change of the number of molecules $\mathrm{N}$ in a bubble can be expressed by

$$
\frac{d N}{d t}=4 \pi R^{2} \cdot J
$$

where $J$ is the net influx of desorbed gas molecules from the liquid through bubble surface into the bubble.

For diatomic species, like $\mathrm{H}_{2}$ and $\mathrm{N}_{2}$,

$$
J=K_{r}\left(c^{2}-c_{R}^{2}\right)
$$

where $K_{r}$ is surface recombination coefficient; $c$ is supersaturated concentration in the liquid and $c_{R}$ is the normal concentration near the bubble surface determined by Sievert's Law corresponding to pressure $P$ in the bubble.

For monoatomic species, like Ar and He,

$$
J=\frac{D\left(c-c_{R}\right)}{R}(18)
$$

Where $D$ is the diffusion coefficient, $c$ is supersaturated concentration and $c_{R}$ is the normal concentration near the bubble surface determined by Henry's Law corresponding to pressure $P$ in the bubble.

For diatomic molecule gas, the normal solubility obeys Sievert's Law, namely:

$$
\frac{c_{R}}{c_{0}}=\sqrt{\frac{P}{P_{l}}}(19)
$$

For monoatomic molecule gas, the solubility obeys Henry's Law, we have

$$
\frac{c_{R}}{c_{0}}=\frac{P}{P_{l}}(20)
$$

With Eq. (10) and Eq. (14) to (20), we can deduce an expression for bubble growth for these two cases, respectively, as below.

Bubble growth rate $d R / d t$ :

$$
\begin{gathered}
\text { for } \mathrm{H}_{2} / \mathrm{N}_{2} \text { (Sievert's Law) } \frac{d R}{d t}=3 k T K_{r}{C_{0}}^{2}\left(\xi^{2}-1-\frac{2 \sigma}{R P_{l}}\right) /\left(3 P_{l}+\frac{4 \sigma}{R}\right)(21) \\
\text { for Ar/He (Henry's Law) } \frac{d R}{d t}=3 k T D c_{0}\left(\xi-1-\frac{2 \sigma}{R P_{l}}\right) /\left(3 P_{l} R+4 \sigma\right)(22)
\end{gathered}
$$

Derivations of Eq. (21) and (22) can be found in the appendix B. Integrating Eq. (21) and (22) in time we can get time-evolution equation for the radius of bubble:

for $\mathrm{H}_{2} / \mathrm{N}_{2}$ (Sievert's Law)

$$
\left[4 \sigma\left(\xi^{2}-1\right)+6 \sigma\right] \ln \left|\left(\xi^{2}-1\right) R-\frac{2 \sigma}{P_{l}}\right|+3\left(\xi^{2}-1\right) P_{l} R=3 k T K_{r} c_{0}{ }^{2}\left(\xi^{2}-1\right)\left(t-C_{0}\right)(23)
$$

for Ar/He (Henry's Law)

$$
\left(16 \sigma^{2}+8 \sigma\right) \ln \left|(\xi-1) R-\frac{2 \sigma}{P_{l}}\right|+3(\xi-1)^{2} P_{l}^{2} R^{2}+4 \sigma(\xi-1)(2 \xi+1) P_{l} R=6 k T D P_{l} c_{0}(\xi-1)^{3}\left(t-C_{0}\right)
$$

where $C_{0}$ is constant and determined by $R(t=0)=R_{c}$ and $R_{c}$ is critical radius of bubble nucleation.

Eq. (21) to (24) are the bubble growth dynamics equations which can be applied to all types of nucleation once a critical bubble has been achieved and the critical radius is dependent on the type of nucleation. To simplify, we take homogeneous nucleation as an example, which is due to atom fluctuation and requires very high supersaturation. At the beginning of nucleation state, considering the initial condition for a bubble with $R=R_{c}$, 
and $c_{R}=c$, according to Eq. (15), (19) and (20) we can get supersaturation ratio required to achieve homogeneous nucleation at a known critical radius: [57]

$$
\begin{gathered}
\xi=\sqrt{\frac{2 \sigma}{R_{c} \cdot P_{l}}+1} \text { for } \mathrm{H}_{2} / \mathrm{N}_{2}(\text { Sievert's Law) (25) } \\
\xi=\frac{2 \sigma}{R_{c} \cdot P_{l}}+1 \text { for } \mathrm{Ar} / \mathrm{He}(\text { Henry's Law) (26) }
\end{gathered}
$$

In order to form and achieve the growth of a critical bubble, for instance $R_{c} \sim 0.1 \mu \mathrm{m}$, from Eq. (25) a supersaturation ratio around 300 and 1040 is required for liquid Sn in H plasma in Nano-PSI and Magnum-PSI, respectively, which can be easily fulfilled corresponding to Figure 11 (b). While, from Eq. (26) the required supersaturation ratio for liquid $\mathrm{Sn}$ in $\mathrm{Ar} / \mathrm{He}$ is $1.66 \times 10^{5}$ at $65 \mathrm{~Pa}$, which is not fulfilled at high temperature according to Figure 11 (c). This suggests that homogeneous nucleation could be not possible for liquid Sn exposed to Ar/He plasma in our experiment. Figure 12 (a) and (b) display some examples of bubble growth rate (Eq. (21) and (22)) and bubble radius time-evolution (Eq. (23) and (24)), respectively, assuming a critical $R_{c} \sim 0.1 \mu \mathrm{m}$ according to above estimations, namely supersaturation 300 and 1040 were used for $\mathrm{H}$ cases, while for Ar and $\mathrm{He}$, the supersaturation from Figure 11 (c) was used. The temperature was taken as $700{ }^{\circ} \mathrm{C}$ for $\mathrm{H}$ and $1000{ }^{\circ} \mathrm{C}$ for $\mathrm{Ar}$ and $\mathrm{He}$ as this is close to the experiment temperature in Figure 4 (a) and Figure 10. In Figure 12 (a), for the cases of $\mathrm{Ar}$ and $\mathrm{He}$ when bubble radius is below $\sim 4 \mu \mathrm{m}$, a negative growth rate is presented (not shown in the figure), which indicates that those $\mathrm{Ar} / \mathrm{He}$ bubbles smaller than $4 \mu \mathrm{m}$ cannot grow. Compared with $\mathrm{Ar} / \mathrm{He}$, hydrogen bubble can achieve its growth even at very small size scale and its growth rate can be several orders of magnitude high. The radius time-evolution of a bubble can be seen in Figure 12 (b). For Sn in H plasma, it only takes $1-2 \mathrm{~s}$ for a bubble to grow into several hundred micrometers, while for Ar or He it would take tens of seconds. In should be remarked that the supersaturation ratio used for $\mathrm{H}$ case is the low bound and it can be larger according to Figure 11 (b) and other non-homogeneous nucleation is also possible. This implies that bubble growth can be even faster.
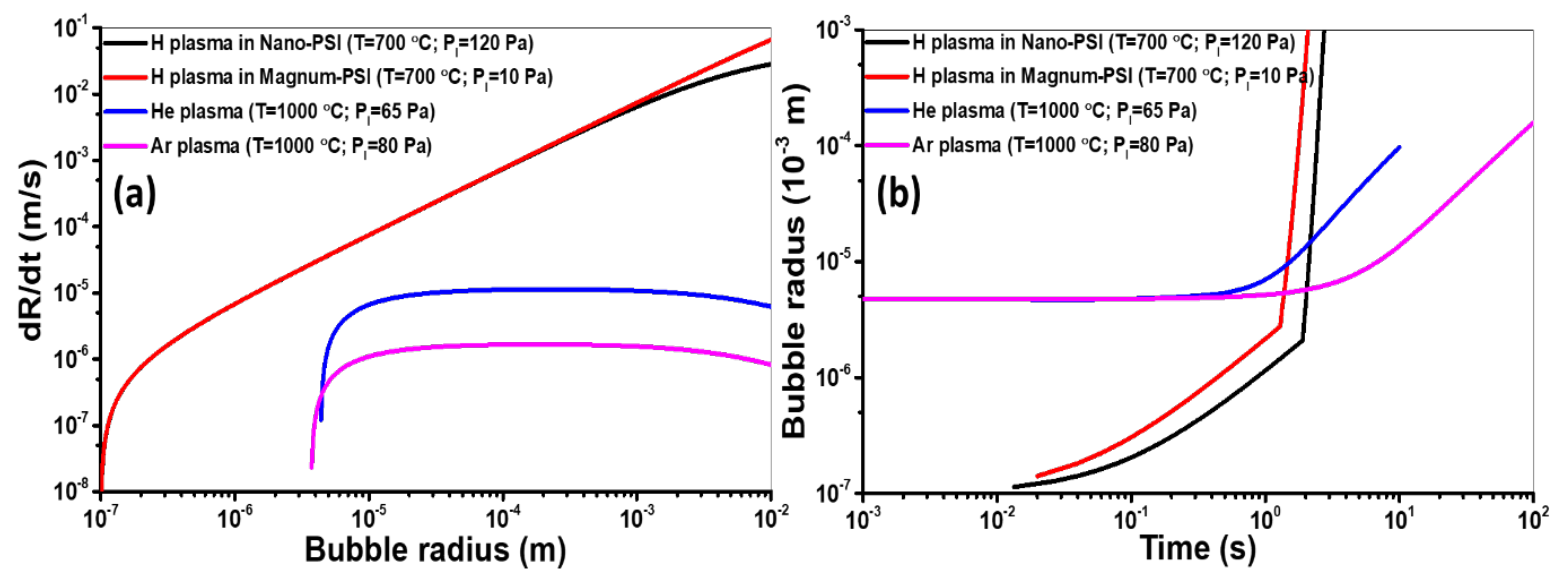

Figure 12 (a) Bubble grow rate, calculated from Eq. (21) and (22), as a function of bubble radius for the examples of Sn in $H$ plasma in Nano-PSI/Magnum-PSI and Sn in Ar/He plasma; (b) time-evolution of bubble radius for the examples in (a), calculated from Eq. (23) and (24).

These analysis and examples can give us some indications and general trends as to how a bubble grows under our exposure conditions. The actual growth of a bubble is more complicated. To make an accurate prediction of bubble growth, more accurate solubility and diffusion data are required. When compared to the bubble growth in $\mathrm{H}-$ supersaturated liquid $\mathrm{Sn}$, the bubble growth in $\mathrm{Ar} / \mathrm{He}$-supersaturated is quite slow. This is in agreement with our observation as shown in section 3 .

In our experiment droplet ejection, namely bubble formation, was only observed for liquid Sn exposed to high flux and high temperature Ar and He plasmas. According to our experiments, we presented a plot in Figure 13 below, which shows some possible plasma conditions for an unstable/stable liquid Sn surface due to Ar and He plasma exposures, respectively. For these monoatomic molecule plasmas, a high supersaturation ratio and high bulk concentration can be only achieved under high flux plasma implantation, which makes it possible for bubble formation and growth. Our experiments also show that high temperature is required for droplet ejection from liquid Sn under He/Ar plasma, as shown in Figure 13, as Eq. (21) and (22) imply that at aiven supersaturation ratio 
bubble growth rate mainly relies on temperature $T$ and normal solubility $\mathrm{c}_{0}$, while the latter also increases with the increasing temperature. Additionally, nucleation, as the prerequisite for bubble formation, can be significantly influenced by temperature. According to Classical Nucleation Theory (CNT) [55], both homogeneous and heterogeneous nucleation rates increase with temperature as scaling $\sim e^{-1 / T}$. It also should be noted that at high temperature the presence of liquid Sn vapor inside bubbles shouldn't be neglected, which could possibly facilitate the growth of bubble. For the bubble formation due to vapor pressure, the generalized Rayleigh-Plesset equation can be used to describe its growth [56] however we will not discuss this further. However, in some cases it can be an important or even dominant mechanism. One extreme example is bubble formation due to liquid boiling at boiling point. In our previous work [25], we have observed $\mathrm{Sn}$ droplet ejection due to boiling in vacuum of $10^{-5}$ $\mathrm{Pa}$ at $\mathrm{T} \sim 800{ }^{\circ} \mathrm{C}$.
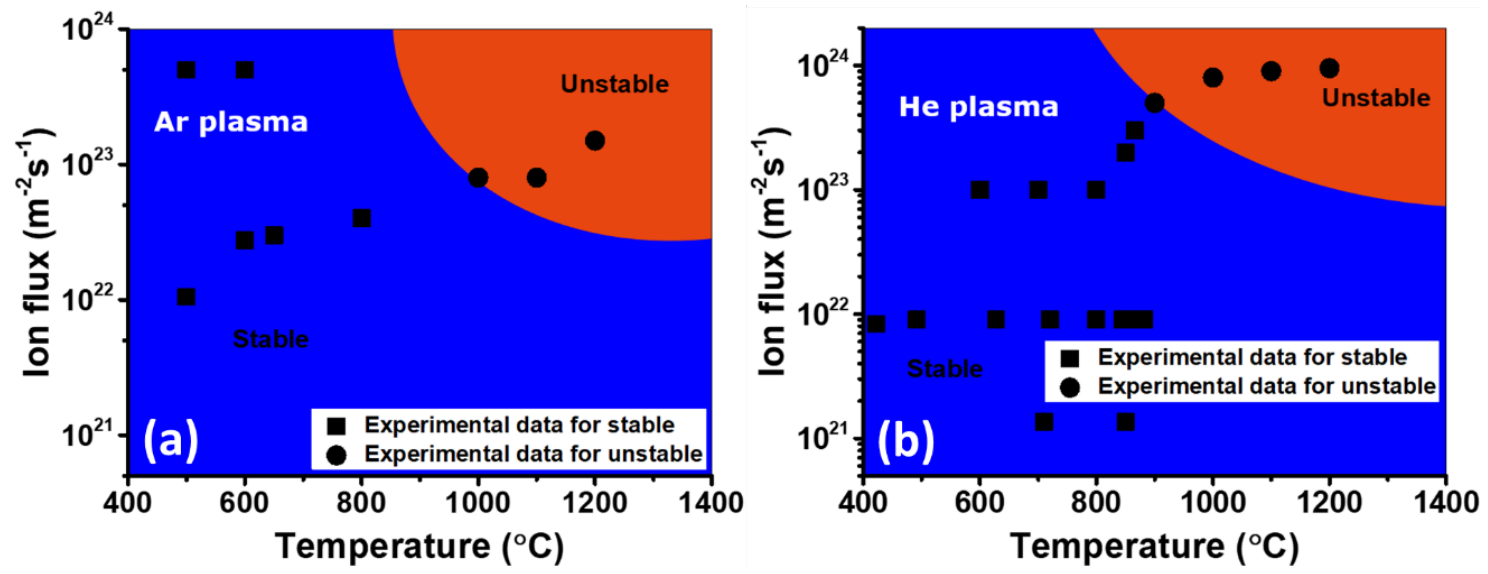

Figure 13 Experimental and possible plasma conditions causing an unstable liquid Sn surface for (a) Ar plasma and (b) He plasma.

\subsection{Production and decomposition of Sn hydride/nitride}

In section 4.1 and 4.2 we have discussed the achievement of high supersaturation due to plasma-enhanced solubility or high flux plasma implantation that could lead to bubble formation and thus droplet ejection. In this section we will discuss whether the chemical interaction of $\mathrm{H}$ and $\mathrm{N}$ plasmas with Sn could also possibly have an influence on liquid Sn surface behaviors. Hydrogen radicals can chemically react with Sn and produce Sn hydride, namely stannane $\left(\mathrm{SnH}_{4}\right)$ [26]. Hydrogen has been applied for mirror cleaning in the EUV industry to remove tin via stannane formation [58]. Recently, Manhard also reported Sn erosion due to H plasma exposure [38]. When $\mathrm{Sn}$ is exposed to nitrogen plasma, it is also possible to form $\mathrm{Sn}$ nitride $\left(\mathrm{Sn}_{3} \mathrm{~N}_{4}\right)$, which is sometimes considered an attractive candidate material for optical and electronic applications [37, 59]. As both hydrogen and nitrogen are diatomic molecular gases, both Sn hydride and nitride are volatile, and also the behaviors of liquid Sn exposed to $\mathrm{H}$ and $\mathrm{N}$ plasmas were quite similar, we will discuss both together here. Their formation and decomposition processes can be expressed as below:

$$
\begin{gathered}
\mathrm{Sn}+4 \mathrm{H} \rightarrow \mathrm{SnH}_{4} \stackrel{\sim 25^{\circ} \mathrm{C}}{\longrightarrow} \mathrm{Sn}+2 \mathrm{H}_{2} \\
3 \mathrm{Sn}+4 \mathrm{~N} \rightarrow \mathrm{Sn}_{3} \mathrm{~N}_{4} \stackrel{360-450^{\circ} \mathrm{C}}{\longrightarrow} 3 \mathrm{Sn}+2 \mathrm{~N}_{2}
\end{gathered}
$$

Stannane is an unstable gas and can decompose into elementary $\mathrm{Sn}$ and $\mathrm{H}_{2}$ molecules at room temperature [60][61]. Its decomposition reaction is a first-order reaction and in 1956 Tamaru has studied the thermal decomposition process of stannane on Sn surface experimentally for the first time [26]. From Tamaru's experimental data, we can use Arrhenius equation to fit the rate coefficient of its decomposition reaction, which is shown below:

$$
k=620.93 e^{-\frac{4570.6}{T}} S^{-1}(29)
$$

where $T$ is the temperature in $\mathrm{K}$. Then the half-life $t_{1 / 2}$ of stannane can be calculated by $t_{1 / 2}=\frac{\ln 2}{k}$. For instance, at temperature 400 and $800{ }^{\circ} \mathrm{C}$, the half-time is around 1 and $0.04 \mathrm{~s}$, respectively. In our experiments, after some bubbles were detected with the camera it only took $\sim \mathrm{ms}$ before they bursted and from the model prediction in section 4.2, the growth time of a bubble is possibly several seconds or even shorter. This could indicate that 
stannane or H-Sn compounds could diffuse into bubbles and decompose, thus facilitating the bubble growth. Since little data is available for the diffusion and dissolution of stannane in liquid Sn however we cannot further discuss how stannane (or H-Sn compounds) influences bubble growth. Sn nitride is a metastable solid that can be produced by the interaction of $\mathrm{N}$ radicals with $\mathrm{Sn}$ atoms. Maruyama reported a decomposition temperature at $\sim 360{ }^{\circ} \mathrm{C}$ [44], while Lima found it can be stable up to $\sim 450{ }^{\circ} \mathrm{C}$ and even at $\sim 550{ }^{\circ} \mathrm{C}$ Sn nitride was still traced [62]. In section 3.1 , we have observed eruptive ejection of $\mathrm{Sn}$ droplets once temperature increased beyond temperatures in the range $520 \sim 540{ }^{\circ} \mathrm{C}$ for liquid $\mathrm{Sn}$ exposed to $\mathrm{N}$ plasma. A solid-like layer can be seen below this temperature on the liquid Sn (This can be observed in Supplementary File 3) and we suspect this layer could be Sn nitride film. The presence of this solid film may lead to the formation of very large bubbles as seen in Figure 3 (b) by acting as a sort of "skin" on the surface, making it hard to break by bubble bursting. As the temperature increased above $\mathrm{Sn}$ nitride decomposition temperature, such big bubbles disappeared due to the decomposition and ejection of $\mathrm{Sn}$ nitrides. The peak at $\sim 26 \mathrm{~s}$ in Figure 4 (c) shows a brief burst of intense droplet production which may be associated with the break-up of the nitride layer. The existence of solid Sn nitride in liquid Sn could also provide a lot of nucleation sites for bubble formation and growth. We have exposed Sn targets to H-He (gas flow ratio, H:He $1: 2)$ and $\mathrm{N}-\mathrm{He}(\mathrm{N}: \mathrm{He} \sim 2: 7)$ mixed plasmas, respectively. The addition of He allowed the source to operate steadily while reducing the heat flux so that an exposure temperature below Sn melting point could be achieved. These exposures showed that for the case of $\mathrm{N}-\mathrm{He}$ mixed plasma, there was no clear droplet ejection observed at temperatures below $\sim 400{ }^{\circ} \mathrm{C}$, while when the temperature was raised up to $450 \sim 500{ }^{\circ} \mathrm{C}$ very tiny droplets can be seen by eyes, which cannot be visiable by fast camera. For the case of Sn exposed to H-He mixed plasma, very tiny droplets were observed once Sn began to melt.

The above discussion has suggested that the production and decomposition of stannane and Sn nitride could possibly have an influence on bubble formation and growth. However, as stannane can decompose very fast at room temperature, it is difficult to directly verify its existence in our experiments. While a relative high decomposition temperature of Sn nitride makes it possible to be detected directly. Figure 14 exhibits XPS spectra for three Sn samples: one pure Sn sample before plasma exposure and two $\mathrm{Sn}$ samples ( $\mathrm{Sn} / \mathrm{Si}$ and $\mathrm{Sn} / \mathrm{W})$ after NHe mixed plasma exposure with silican and tungsten as substrate, respectively, at a temperature of $\sim 280{ }^{\circ} \mathrm{C}$. A very clear N 1s peak at $\sim 397 \mathrm{eV}$ was presented for those Sn samples exposed to N-He mixed plamsa, which is the direct evidence for the existence of Sn nitirde [37]. No N peak was found for the one without exposure. Their surface compositions have been summarized in Table 3. Obviously, the Sn nitride indeed existed in Sn samples during $\mathrm{N}$ plasma exposure.

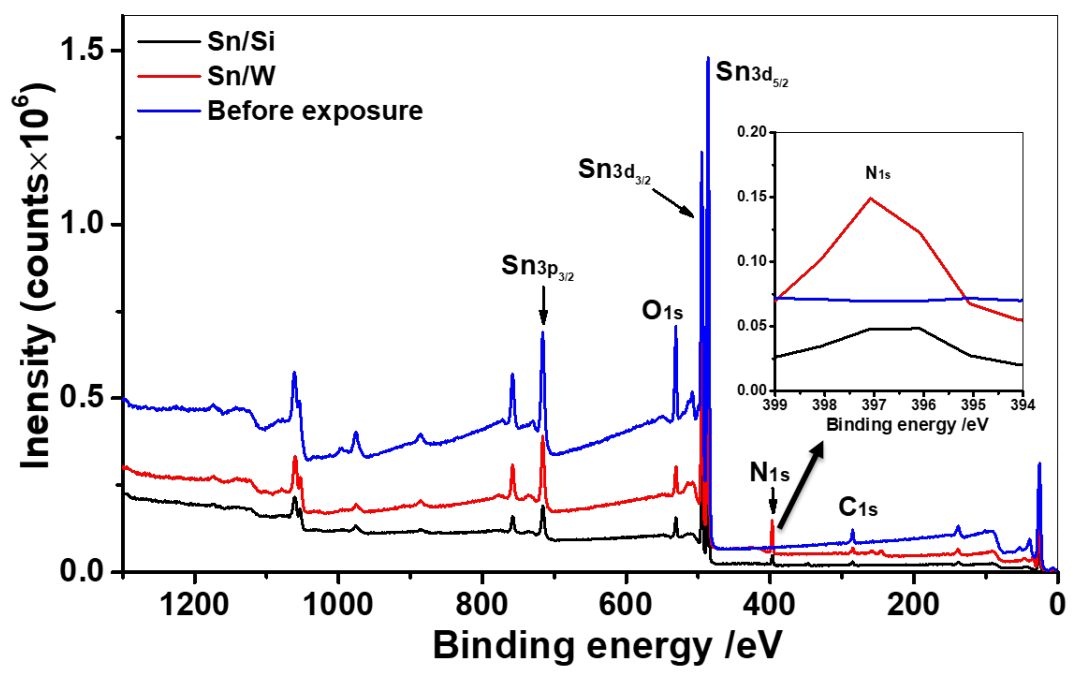

Figure 14 XPS spectra of one Sn sample before exposure and two Sn samples after N-He mixed plasma exposure at $\sim 280^{\circ} \mathrm{C}$. 
Table 3 Surface composition of tin after N-He mixed plasma exposure

\begin{tabular}{ccccc}
\hline Sn samples & C (atomic \%) & O (atomic \%) & Sn (atomic \%) & N (atomic \%) \\
\hline Before exposure & 20 & 49.2 & 30.8 & 0 \\
$\mathrm{Sn} / \mathrm{Si}$ & 17.8 & 33.4 & 24.8 & 21.8 \\
$\mathrm{Sn} / \mathrm{W}$ & 13.5 & 24.3 & 28.2 & 33.0 \\
\hline
\end{tabular}

\section{Discussion}

Previous work $[1,12,21,22]$ have proved that surface instability of liquid metals due to MHD forces can be avoided by using CPS mesh. However, this is not the case for liquid Sn exposed to plasmas in our experiments, in which the ejection of many Sn droplets was still observed even without magnetic field. Such behaviors of surface instability and droplet ejection of liquid Sn are highly correlated with plasma species and can be signficantly influenced by plasma fluxes and exposure temperature.

In this work, bubble formation and bursting are proposed as the main mechanism that is responsible for the surface instability behavior and droplet ejection of liquid Sn. Even though it is not possible to directly detect bubble formation and bursting in Magnum-PSI, due to the similar surface behaviors and droplet ejection velocity of liquid Sn to that exposed in Nano-PSI, we can still attribute bubble formation and bursting to these droplets produced in Magnum-PSI. Additionally, surface oscillation presumably due to mesh expanding and shrink has been observed in Magnum-PSI for a CPS liquid Sn exposed to deuterium plasma in our previous experiment [25] (see Supplementary File 8), which could also be an evidence for gas bubble formation.

The formation and growth of bubbles in liquid Sn not only lead to the ejection of droplets into plasma but also could unexpectedly creat a huge pressure difference between components and cause potential threats. Figure 15 displays some photos from the experiments, in which (a) is a damaged mesh which presumably became damaged by expanding to release high pressure resulting from the accumulation of $\mathrm{H}_{2}$ gas in the cup. As the mesh was totally wetted by liquid Sn the big hydrogen bubbles formed inside the cup couldn't directly escape through the mesh and therefore appear to have forced this damage on the mesh. Figure 15 (b) shows a TZM cup filled with Sn exposed to hydrogen plasma that was ejected up in Nano-PSI (see Supplementary File 9). This is because there was a big gap between the cup and the target holder. In the previous exposure, some liquid Sn was pushed out of the cup and flowed into the gap. As the whole target holder was also soaked in the hydrogen plasma, the pressure in the gap increased due to more and more hydrogen desorbing from liquid Sn and finally this high pressure made the cup suddenly ejected up. Figure 15 (c) is a CPS liquid Sn target exposed to deuterium plasma at $\sim 850{ }^{\circ} \mathrm{C}$ in Magnum-PSI from previous experiment [25] and (d) displays the center area of (c), in which the mesh was destroyed and a gap in the center can be seen. This could be due to the loss of Sn during the exposure. This lead to a small gap between the mesh and liquid Sn bulk, thus leading to the isolation of the mesh in this area. The expanding of the mesh possibly due to massive hydrogen desorbing from liquid Sn around it could also lead to its isolation from the bulk Sn (see Supplementary File 8). Therefore, the mesh was heated by the plasma beam to high temperature and reached its melting point. Figure 15 could therefore imply that CPS mesh may not be a good choice for the design of liquid Sn targets. 


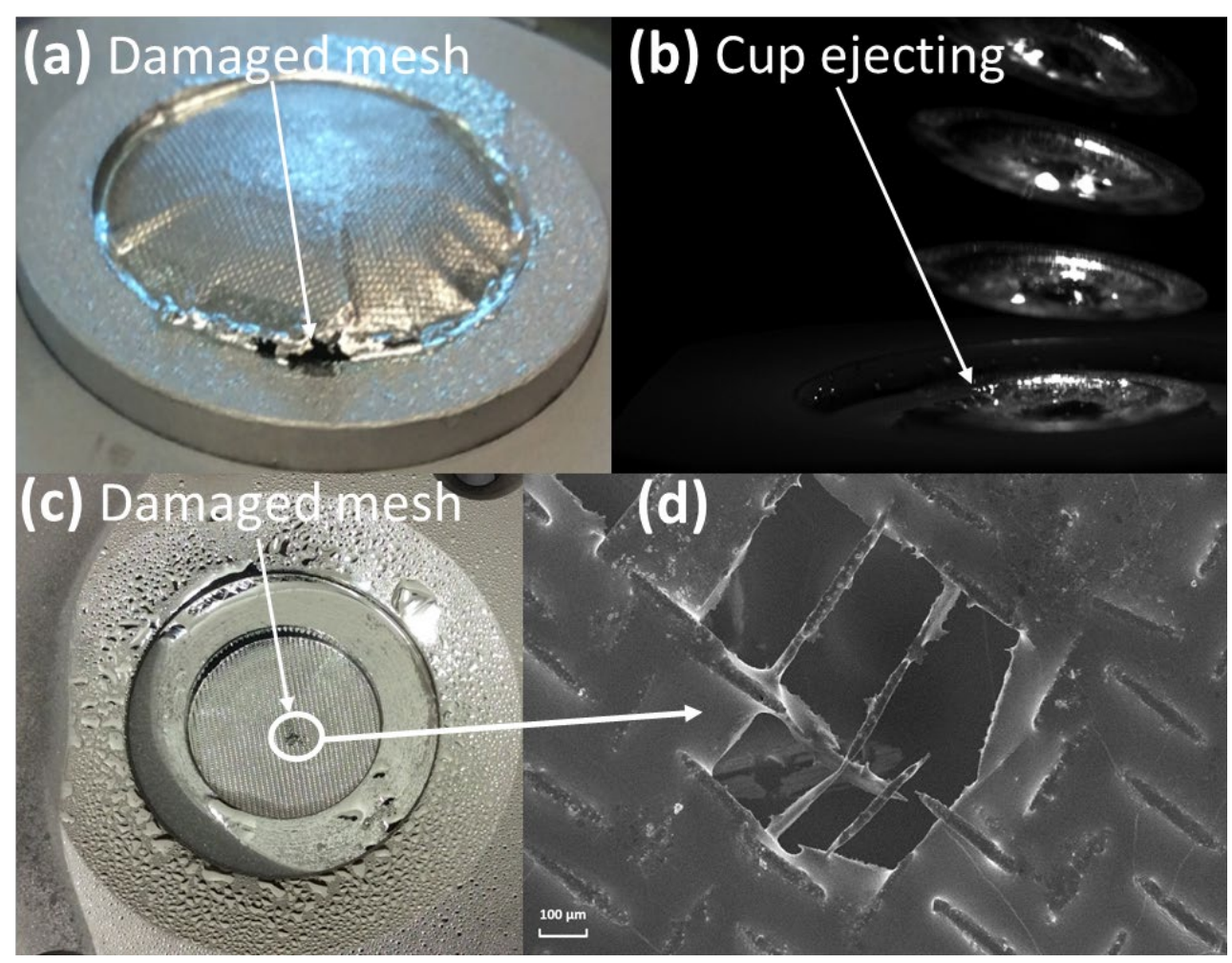

Figure 15 (a) Mesh damaging of CPS liquid Sn in H plasma in Nano-PSI; (b) ejection up of a cup filled of Sn in Nano-PSI (see Supplementary video 9); (c) a CPS liquid Sn target exposed to deuterium plasma in Magnum-PSI at $\sim 850{ }^{\circ} \mathrm{C}$ and (d) is a SEM picture of the hole in the centre area of (c)

As a potential liquid metal material for future fusion reactors, Sn core concentration must be controlled below a very low level and Sn droplets which can enter the core plasma must be avoided to prevent disruptions. Thus, good control and limitation of Sn droplets are necessary. In this work, it has been suggested that droplets from liquid Sn exposed to hydrogen plasma presumably cannot be avoided, however, the application of CPS meshes can indeed suppress droplet ejection and decrease droplet size and density. In the experiment we have found that small pore size mesh can not only make Sn droplets smaller but also decrease droplet densities. With CPS meshes applied, there is a risk that CPS meshes could get destroyed due to the high pressure that is generated from the accumulation of gas bubbles. The formation of gas bubbles below CPS meshes could also isolate meshes from liquid Sn bulk, thus leading to mesh melting. Even though CPS meshes may not be a good choice for liquid Sn, other smarter designs with small pore sizes, such as 3D-printed design [5] and sponge structure, could be a better choice. What's more, the velocities of most ejected Sn droplets are in the range of $1 \sim 5 \mathrm{~m} / \mathrm{s}$ and cannot travel too far as they can be deflected by the plasma ion drag or brought back to the divertor surface by electric fields once they are ionized. As the achievement of plasma-species-supersaturated liquid Sn has been proposed to be mainly responsible for bubble formation and droplet ejection in this experiment, in order to avoid droplet ejection prevention of supersaturation of liquid $\mathrm{Sn}$ is necessary, especially under $\mathrm{H}$ plasma. A possible solution is to add other elements, like lithium, which have good affinity with $\mathrm{H}$ into liquid tin to form stable hydride and deplete these dissolved $\mathrm{H}$ atoms in tin. We do not observe lithium droplets under hydrogen isotope plasmas even at very high flux up to $10^{24} \mathrm{~m}^{-2} \mathrm{~s}^{-1}$ in our lithium experiments [63], while droplet ejection under high helium ion flux plasma loadings still exists. In the view of surface instability, lithium-tin alloys could be a better choice. Further assessment of droplet production in confinement devices is therefore necessary and the key to accurately predicting the influence on fusion performance.

\section{Conclusions}

In this work, surface instability and droplet ejection of liquid Sn surface under different plasma loadings have been observed and systematically researched for the first time. Droplet ejection was observed under a wide variety of both high-flux and low-flux plasma conditions. Droplet production was not entirely avoided by the CPS meshes used in the experiment, however, the meshes with small pore sizes indeed can suppress droplet ejecting and reduce the sizes and densities of droplets. In hydrogen plasma, droplets were found to be ejected once Sn melted, while, 
for the case of nitrogen plasma ejection of droplets occurred at higher temperature around $450 \sim 500{ }^{\circ} \mathrm{C}$. The difference could be due to the higher decomposition temperature of Sn nitride. In argon and helium plasmas, the liquid Sn surface only behaved unstably at very high fluxes and high temperatures, which was accompanied by very low droplet densities compared with hydrogen and nitrogen plasmas. The ejection velocities of most droplets were in the range of $1 \sim 5 \mathrm{~m} / \mathrm{s}$ and some ejected droplets were observed to be entrained by the plasma and return to the liquid surface.

Bubble formation and bursting was directly observed and recorded and is proposed as the main mechanism for droplet ejection in this experiment. A model based on the desorption of dissolved plasma species in the supersaturated liquid was built to describe the growth of bubbles. Diatomic molecule species, such as $\mathrm{H}_{2}$ and $\mathrm{N}_{2}$, obey Sievert's law at the gas-liquid interface, while monoatomic molecule species, such as Ar and He, obey Henry's law. This leads to the different behaviors in the formation and growth of bubbles for liquid Sn exposed to different types of plasmas. The concentration of $\mathrm{H}$ or $\mathrm{N}$ in the liquid can be extremely high due to plasma-enhanced solubility, leading to a high supersaturation ratio. Whereas, a high concentration of Ar or He can be only achieved by high flux plasma implantation. Once a certain supersaturation ratio and a certain bulk concentration are reached, these dissolved species can desorb resulting into the nucleation and growth of bubbles. The bursting of these bubbles will finally eject out $\mathrm{Sn}$ droplets. The formation and decomposition of Sn hydride and nitride could also have an influence on the surface behavior of liquid Sn as the existence of Sn nitride has been demonstrated. But it is still not clear how Sn hydride and nitride influence the surface behaviors due to scarce data about their properties in liquid Sn.

Overall the results indicate that the choice of layered mesh CPS used with Sn may have challenges for application as a plasma facing material in future fusion reactors as bubble and droplet formation can lead to damage and failure of the mesh. The choice of 3D-connected materials such as sponges, felts or 3D-printed structures should be investigated to determine if splashing due to bubble formation is inevitable or can be avoided by careful choice of CPS design. It also motivates investigation of whether $\mathrm{SnLi}$ alloys may be more suitable in avoiding bubble formation.

\section{Acknowledgements}

DIFFER is part of the institutes organization of NWO. This work has been carried out within the framework of the EUROfusion Consortium and has received funding from the Euratom research and training programme 20142018 and 2020-2024 under grant agreement No. 633053. The views and opinions expressed herein do not necessarily reflect those of the European Commission. We acknowledge the support of the Magnum-PSI Facility Team at DIFFER. The Magnum-PSI facility at DIFFER has been funded by the Netherlands Organisation for Scientific Research (NWO) and EURATOM.

\section{Appendices}

\section{A. calculation of Gibbs free energy}

If $x$ is the $\mathrm{H}$ dissolving fraction in liquid $\mathrm{Sn}$, then the $\mathrm{H}_{2}$ molecule dissolution reaction Eq. (1) is more accurately expressed by

$$
\frac{1}{2} \mathrm{H}_{2(\mathrm{~g})}+\frac{1}{x} \mathrm{Sn}_{(\mathrm{L})} \leftrightarrow \frac{1}{x}\left[\mathrm{SnH}_{\mathrm{x}}\right]
$$

As in our previous discussion in [25], this dissolution process can be divided into two steps, namely dissociation of hydrogen molecules $\mathrm{H}_{2}$ into $\mathrm{H}$ atoms and dissolution of $\mathrm{H}$ atoms in liquid $\mathrm{Sn}$, which can be expressed, respectively, as below:

$$
\begin{gathered}
\frac{1}{2} \mathrm{H}_{2(\mathrm{~g})} \leftrightarrow \mathrm{H}_{(\mathrm{g})} \quad(\mathrm{A} 2) \\
\mathrm{H}_{(\mathrm{g})}+\frac{1}{x} \mathrm{Sn}_{(\mathrm{L})} \leftrightarrow \frac{1}{x}\left[\mathrm{SnH}_{\mathrm{x}}\right]_{(\mathrm{L})} \quad(\mathrm{A} 3)
\end{gathered}
$$

As the standard Gibbs energy change of a reaction is the difference of standard formation Gibbs energy between all products and all reactants, then standard formation Gibbs energy change for Eq. (A1) and (A3) can be expressed by: 


$$
\begin{aligned}
\Delta G_{H 2}^{0} & =\frac{1}{x} \Delta G_{f}^{0}([\mathrm{SnHx}])-\frac{1}{2} \Delta G_{f}^{0}\left(\mathrm{H}_{2(\mathrm{~g})}\right)-\frac{1}{x} \Delta G_{f}^{0}([\mathrm{Sn}])(\mathrm{A} 4) \\
\Delta G_{H}^{0} & =\frac{1}{x} \Delta G_{f}^{0}([\mathrm{SnHx}])-\frac{1}{x} \Delta G_{f}^{0}([\mathrm{Sn}])-\Delta G_{f}^{0}(H(\mathrm{~g}))(\mathrm{A} 5)
\end{aligned}
$$

Combine (A4) and (A5), we can get

$$
\begin{gathered}
\Delta G_{H}^{0}=\left[\Delta G_{H 2}^{0}+\frac{1}{2} \Delta G_{f}^{0}\left(\mathrm{H}_{2(\mathrm{~g})}\right)+\frac{1}{x} \Delta G_{f}^{0}([\mathrm{Sn}])\right]-\frac{1}{x} \Delta G_{f}^{0}([\mathrm{Sn}])-\Delta G_{f}^{0}(H(\mathrm{~g}))=\Delta G_{H 2}^{0}+\frac{1}{2} \Delta G_{f}^{0}\left(\mathrm{H}_{2(\mathrm{~g})}\right)- \\
\Delta G_{f}^{0}(H(\mathrm{~g}))(\mathrm{A} 6)
\end{gathered}
$$

Using the definition of standard formation Gibbs energy of a substance, Eq. (A6) can be rewritten by

$$
\Delta G_{H}^{0}=\Delta G_{H 2}^{0}+\left(\frac{1}{2} \Delta H_{f}^{0}(H 2(\mathrm{~g}))-\frac{1}{2} T \cdot \Delta S_{f}^{0}(H 2(\mathrm{~g}))\right)-\left(\Delta H_{f}^{0}(H(\mathrm{~g}))-T \cdot \Delta S_{f}^{0}(H(\mathrm{~g}))\right)
$$

According to literatures [64], $\Delta H_{f}^{0}(H 2(\mathrm{~g}))=0 \mathrm{JK}^{-1} \mathrm{~mol}^{-1}, \Delta S_{f}^{0}(H 2(\mathrm{~g}))=130.68 \mathrm{JK}^{-1} \mathrm{~mol}^{-1}$ and $\Delta H_{f}^{0}(H(\mathrm{~g}))=$ $217.998 \mathrm{JK}^{-1} \mathrm{~mol}^{-1}, \Delta S_{f}^{0}(H(\mathrm{~g}))=114.717 \mathrm{JK}^{-1} \mathrm{~mol}^{-1}$, and using $\Delta G_{H 2}^{0}$ from Eq. 3 we can get

$$
\Delta G_{2}^{0}=55.64 \cdot T-94991.46 \mathrm{~J} \cdot \mathrm{mol}^{-1}
$$

\section{B. Derivation of the radius for bubble growth}

Substituting $P$ in Eq. (14) with Eq. (15) we can get:

$$
\frac{3 k T}{4 \pi} N=P_{l} R^{3}+2 \sigma R^{2}
$$

Differentiating both sides of Eq. (B1) with time $t$ gives us:

$$
\frac{3 k T}{4 \pi} \cdot \frac{d N}{d t}=\left(3 R^{2} P_{l}+4 \sigma R\right) \frac{d R}{d t}(\mathrm{~B} 2)
$$

For diatomic molecule species, using Eq. (10) (16) (17) and (19) we can get bubble growth rate equation:

$$
\frac{d R}{d t}=3 k T K_{r} c_{0}^{2}\left(\xi^{2}-1-\frac{2 \sigma}{R P_{l}}\right) /\left(3 P_{l}+\frac{4 \sigma}{R}\right)(
$$

For monoatomic species, exploiting Eq. (10) (16), (18) and (20) into Eq.(B2) we have

$$
\frac{d R}{d t}=3 k T D c_{0}\left(\xi-1-\frac{2 \sigma}{R P_{l}}\right) /\left(3 P_{l} R+4 \sigma\right)(\mathrm{B} 4)
$$

\section{Reference}

[1] J W Coenen, G De Temmerman, G Federici, V Philipps, G Sergienko, G Strohmayer, A Terra, B Unterberg T W and D C M V den B 2014 Liquid metals as alternative solution for the power exhaust of future fusion devices: status and perspective Phys. Scr. T159 014037

[2] Morgan T W, Rindt P, Van Eden G G, Kvon V, Jaworksi M A and Cardozo N J L 2018 Liquid metals as a divertor plasma-facing material explored using the Pilot-PSI and Magnum-PSI linear devices Plasma Phys. Control. Fusion 6014025

[3] Van Eden G G, Kvon V, Van De Sanden M C M and Morgan T W 2017 Oscillatory vapour shielding of liquid metal walls in nuclear fusion devices Nat. Commun. 8192

[4] Rindt P, Morgan T W, Jaworski M A and Lopes Cardozo N J 2018 Power handling limit of liquid lithium divertor targets Nucl. Fusion 58104002

[5] Rindt P, Mata González J, Hoogerhuis P, van den Bosch P, van Maris M, Terentyev D, Yin C, Wirtz M, Lopes Cardozo N J, van Dommelen J A W and Morgan T W 2019 Using 3D-printed tungsten to optimize liquid metal divertor targets for flow and thermal stresses Nucl. Fusion $\mathbf{5 9} 054001$

[6] Antar G Y, Doerner R P, Kaita R, Majeski R, Spaleta J, Munsat T, Jones B, Maingi R, Soukhanovskii V, Kugel H, Timberlake J, Krasheninnikov S I, Luckhardt S C and Conn R W 2002 Plasma-lithium interaction in the CDX-U spherical torus Fusion Eng. Des. 60 157-66 
[7] Whyte D G, Evans T E, Wong C P C, West W P, Bastasz R, Allain J P and Brooks J N 2004 Experimental observations of lithium as a plasma-facing surface in the DIII-D tokamak divertor Fusion Eng. Des. 72 133-47

[8] Wang Z H, Jia X and Ni M J 2018 Effect of the magnetic field and current orientation on the splashing of liquid metal free surface of fusion reactor PFCs Nucl. Fusion 58126011

[9] Tabarés F L 2015 Present status of liquid metal research for a fusion reactor Plasma Phys. Control. Fusion 58014014

[10] Fiflis P, Christenson M, Szott M, Kalathiparambil K and Ruzic D N 2016 Free surface stability of liquid metal plasma facing components Nucl. Fusion 56106020

[11] Miloshevsky G and Hassanein A 2014 Stability and erosion of melt layers developed on plasma facing components of tokamaks Nucl. Fusion 54043016

[12] Jaworski M A, Abrams T, Allain J P, Bell M G, Bell R E, Diallo A, Gray T K, Gerhardt S P, Kaita R, Kugel H W, Leblanc B P, Maingi R, McLean A G, Menard J, Nygren R, Ono M, Podesta M, Roquemore A L, Sabbagh S A, Scotti F, Skinner C H, Soukhanovskii V A and Stotler D P 2013 Liquid lithium divertor characteristics and plasma-material interactions in NSTX high-performance plasmas Nucl. Fusion 53083032

[13] Bazylev B, Janeschitz G, Landman I, Loarte A, Klimov N S, Podkovyrovd V L and Safronov V M 2009 Experimental and theoretical investigation of droplet emission from tungsten melt layer Fusion Eng. Des. 84 441-5

[14] Miloshevsky G V. and Hassanein A 2010 Modelling of Kelvin-Helmholtz instability and splashing of melt layers from plasma-facing components in tokamaks under plasma impact Nucl. Fusion $\mathbf{5 0} 115005$

[15] Yang F, Khodak A and Stone H A 2019 The effects of a horizontal magnetic field on the RayleighTaylor instability Nucl. Mater. Energy 18 175-81

[16] Allain J P, Whyte D G and Brooks J N 2004 Lithium erosion experiments and modelling under quiescent plasma conditions in DIII-D Nucl. Fusion 44 655-64

[17] Apicella M L, Apruzzese G, Mazzitelli G, Ridolfini V P, Alekseyev A G, Lazarev V B, Mirnov S V. and Zagórski R 2012 Lithization of the FTU tokamak with a critical amount of lithium injection Plasma Phys. Control. Fusion 54035001

[18] Zuo G Z, Ren J, Hu J S, Sun Z, Yang Q X, Li J G, Zakharov L E and Ruzic D N 2014 Liquid lithium surface control and its effect on plasma performance in the HT-7 tokamak Fusion Eng. Des. 89 2845-52

[19] Golubchikov L G, Evtikhin V A, Lyublinski I E, Pistunovich V I, Potapov I N and Chumanov A N 1996 Development of a liquid-metal fusion reactor divertor with a capillary-pore system J. Nucl. Mater. 233$237667-72$

[20] Evtikhin V A, Lyublinski I E, Vertkov A V., Mirnov S V., Lazarev V B, Petrova N P, Sotnikov S M, Chernobai A P, Khripunov B I, Petrov V B, Prokhorov D Y and Korzhavin V M 2002 Lithium divertor concept and results of supporting experiments Plasma Phys. Control. Fusion 44 955-77

[21] Evtikhin V A, Vertkov A V., Lyublinski I E, Khripunov B I, Petrov V B and Mirnov S V. 2002 Research of lithium capillary-pore systems for fusion reactor plasma facing components $J$. Nucl. Mater. 307-311 1664-9

[22] Mirnov S V., Azizov E A, Evtikhin V A, Lazarev V B, Lyublinski I E, Vertkov A V. and Prokhorov D Y 2006 Experiments with lithium limiter on T-11M tokamak and applications of the lithium capillarypore system in future fusion reactor devices Plasma Phys. Control. Fusion 48 821-37

[23] Loureiro J P S, Fernandes H, Tabarés F L, Mazzitelli G, Silva C, Gomes R, Alves E, Mateus R, Pereira T, Figueiredo H and Alves H 2017 Deuterium retention in tin (Sn) and lithium-tin (Li-Sn) samples exposed to ISTTOK plasmas Nucl. Mater. Energy 12 709-13

[24] Cremona A, Vassallo E, Alves E, Causa F, De Iuliis S, Dondè R, Giacomi G, Gervasini G, Granucci G, Iafrati M, Maddaluno G, Mateus R, Minelli D, Mellera V, Nardone A, Pedroni M, Ricci D, Rigato V, 
Rispoli N and Uccello A 2018 Deuterium retention and erosion in liquid Sn samples exposed to D2 and Ar plasmas in GyM device Nucl. Mater. Energy 17 253-8

[25] Ou W, Al R S, Vernimmen J W M, Brons S, Rindt P and Morgan T W 2020 Deuterium retention in Snfilled samples exposed to fusion-relevant flux plasmas Nucl. Fusion $\mathbf{6 0} 026008$

[26] Tamaru K 1956 The Thermal Decomposition of Tin Hydride. J. Phys. Chem. 60 610-2

[27] Baldwin M J, Doerner R P, Luckhardt S C and Conn R W 2002 Deuterium retention in liquid lithium Nucl. Fusion 42 1318-23

[28] David Ruzic 2019 Overview of the Center for Plasma Material Interactions the 6th International Symposium on Liquid Metals Applications for Fusion (ISLA-2019), Illinois, USA

[29] Bystrov K, Morgan T W, Tanyeli I, De Temmerman G and Van De Sanden M C M 2013 Chemical sputtering of graphite by low temperature nitrogen plasmas at various substrate temperatures and ion flux densities J. Appl. Phys. 114133301

[30] Morgan T W, van der Meiden H J, de Kruijf T M, Lof A, Zielinski J J, Scholten J, van Eck H J N, Zeijlmans van Emmichoven P A, De Temmerman G and van den Berg M A 2013 High heat flux capabilities of the Magnum-PSI linear plasma device Fusion Eng. Des. 88 483-7

[31] Rapp J, van Rooij G J, Vijvers W A J, Shumack A E, Lopes Cardozo N J and Schram D C 2010 Experimental and theoretical determination of the efficiency of a sub-atmospheric flowing high power cascaded arc hydrogen plasma source Plasma Sources Sci. Technol. 19065016

[32] Hansen T A R, Weber J W, Colsters P G J, Mestrom D M H G, van de Sanden M C M and Engeln R 2012 Synergistic etch rates during low-energetic plasma etching of hydrogenated amorphous carbon $J$. Appl. Phys. 11213302

[33] de Graaf M J, Severens R, Dahiya R P, van de Sanden M C M and Schram D C 1993 Anomalous fast recombination in hydrogen plasmas involving rovibrational excitation Phys. Rev. E 48 2098-102

[34] Métivier C, Brochard F, Darbouli M and Magnin A 2020 Oscillatory Rayleigh-Bénard Convection in elasto-viscoplastic gels J. Nonnewton. Fluid Mech. 286104428

[35] KNELMAN F, DOMBROWSKI N and NEWITT D M 1954 Mechanism of the Bursting of Bubbles Nature 173261

[36] Schneider C A, Rasband W S and Eliceiri K W 2012 NIH Image to ImageJ: 25 years of image analysis Nat. Methods 9 671-5

[37] Choi S, Kang J, Park J and Kang Y C 2014 Tin nitride thin films fabricated by reactive radio frequency magnetron sputtering at various nitrogen gas ratios Thin Solid Films 571 84-9

[38] Manhard A, Schwarz-Selinger T, Balden M, Dürbeck T, Maier H and Neu R 2020 Deuterium retention in solid and liquid tin after low-temperature plasma exposure Nucl. Fusion 60106007

[39] Shi Y, Miloshevsky G and Hassanein A 2011 Boiling induced macroscopic erosion of plasma facing components in fusion devices Fusion Eng. Des. 86 155-62

[40] Duchemin L, Popinet S, Josserand C and Zaleski S 2002 Jet formation in bubbles bursting at a free surface Phys. Fluids 14 3000-8

[41] Aussems D U B, Khrapak S A, Doğan I, Van De Sanden M C M and Morgan T W 2017 An analytical force balance model for dust particles with size up to several Debye lengths Phys. Plasmas 24113702

[42] Mundra K and Debroy T 1995 A general model for partitioning of gases between a metal and its plasma environment Metall. Mater. Trans. B 26 149-57

[43] Gedeon S A and Eagar T W 1990 Thermochemical analysis of hydrogen absorption in welding Weld. J. 69 264-71

[44] Maruyama T and Morishita T 1995 Tin nitride thin films prepared by radio-frequency reactive sputtering J. Appl. Phys. 77 6641-5 
[45] Palmer T A and Debroy T 2000 Numerical Modeling of enhanced Nitrogen Dissolution During Gas Tungsten Welding Metall. Mater. Trans. B 311371

[46] Humrickhouse P W 2019 An Equation of State and Compendium of Thermophysical Properties of Liquid Tin, a Prospective Plasma-Facing Material IEEE Trans. Plasma Sci. 47 3374-9

[47] Bircumshaw L L 1926 XLII. The solubility of hydrogen in tin and aluminium at high temperatures London, Edinburgh, Dublin Philos. Mag. J. Sci. 1 510-22

[48] Iwasé K 1926 Occlusion of gases by metals and alloys in liquid and solid states Sci. Reports $T^{-}$ohoku Univ. First Ser. 15531

[49] M. B. Bever and C. F. Floe 1944 Solubility of hydrogen in molten coppertin alloys Trans. Am. Inst. Min. Metall. Eng. 156 149-59

[50] Boom R, Dankert O, Veen A V A N and Kamperman A A 2000 Argon Solubility in Liquid Steel Metall. Mater. Trans. B 31B 913-9

[51] Ohno S and Uda M 1981 Effects of hydrogen and nitrogen on blowhole formation in pure nickel at arc welding and non-arc melting Trans. Nat. Res. Inst. Met. 23 243-248

[52] G. Den Ouden; O. Griebling 1990 No Title Recent Trends in Welding Science and Technology ed S.A. David and J.M. Vitek (Asm Intl) pp 431-5

[53] Jones S F, Evans G M and Galvin K P 1999 Bubble nucleation from gas cavities - A review $A d v$. Colloid Interface Sci. 80 27-50

[54] Vachaparambil K J and Einarsrud K E 2018 Explanation of Bubble Nucleation Mechanisms: A Gradient Theory Approach J. Electrochem. Soc. 165 E504-12

[55] Cyr D R 2001 Bubble growth behavior in supersaturated liquid solutions Electronic Theses and Dissertations The University of Maine p 244 (https://digitalcommons.library. umaine.edu/etd/244/)

[56] Plesset M S and Zwick S A 1954 The growth of vapor bubbles in superheated liquids J. Appl. Phys. 25 493-500

[57] Gor G Y and Kuchma A E 2009 Dynamics of gas bubble growth in a supersaturated solution with Sievert's solubility law J. Chem. Phys. 131034507

[58] van Herpen M M J W, Klunder D J W, Soer W A, Moors R and Banine V 2010 Sn etching with hydrogen radicals to clean EUV optics Chem. Phys. Lett. 484 197-9

[59] Caskey C M, Seabold J A, Stevanović V, Ma M, Smith W A, Ginley D S, Neale N R, Richards R M, Lany S and Zakutayev A 2015 Semiconducting properties of spinel tin nitride and other IV3N4 polymorphs J. Mater. Chem. C 3 1389-96

[60] Grochala W and Edwards P P 2004 Thermal decomposition of the non-interstitial hydrides for the storage and production of hydrogen Chem. Rev. 104 1283-315

[61] Ugur D, Storm A J, Verberk R, Brouwer J C and Sloof W G 2012 Generation and decomposition of volatile tin hydrides monitored by in situ quartz crystal microbalances Chem. Phys. Lett. 552 122-5

[62] Lima R S, Dionísio P H, Moro J T, Schreiner W H and Achete C 1994 Thermal evolution and stability of a tin nitride obtained by reactive sputtering Hyperfine Interact. 83 315-9

[63] Ou W, Rindt P, Li K, Arnold Bik W, Morgan T W Deuterium retention and removal in liquid lithium determined by in-situ NRA in Magnum-PSI, to be submitted

[64] David R. Lide, ed., CRC Handbook of Chemistry and Physics, Internet Version 2005, $<$ http://www.hbcpnetbase.com>, CRC Press, Boca Raton, FL, 2005. 